OPEN ACCESS

Edited by:

Rocío Martínez De Pablos,

Universidad de Sevilla, Spain

Reviewed by:

Manuel Sarmiento Soto, University of Oxford, United Kingdom

Laura Annovazzi,

Policlinico di Monza Foundation, Italy

*Correspondence:

Vivaldo Moura-Neto

vivaldomouraneto@gmail.com

tThese authors have contributed equally to this work as first authors.

¥These authors have contributed equally to this work as last authors.

Received: 20 May 2018 Accepted: 16 July 2018 Published: 03 August 2018

Citation:

Matias D, Balça-Silva J, da Graça GC, Wanjiru CM, Macharia $L W$, Nascimento CP, Roque NR, Coelho-Aguiar JM, Pereira CM,

Dos Santos MF, Pessoa LS, Lima FRS, Schanaider A, Ferrer VP, Spohr

TCLS and Moura-Neto V (2018) Microglia/Astrocytes-Glioblastoma

Crosstalk: Crucial Molecular Mechanisms and Microenvironmental Factors.

Front. Cell. Neurosci. 12:235. doi: 10.3389/fncel.2018.00235

\section{Microglia/Astrocytes-Glioblastoma Crosstalk: Crucial Molecular Mechanisms and Microenvironmental Factors}

Diana Matias ${ }^{1,2 \dagger}$, Joana Balça-Silva1,3,4t, Grazielle C. da Graça1, Caroline M. Wanjiru1,2, Lucy W. Macharia'1,5, Carla Pires Nascimento ${ }^{1,5}$, Natalia R. Roque1, Juliana M. Coelho-Aguiar1, Cláudia M. Pereira6, Marcos F. Dos Santos², Luciana S. Pessoa ${ }^{1}$, Flavia R. S. Lima ${ }^{2}$, Alberto Schanaider ${ }^{7}$, Valéria P. Ferrer' ${ }^{1 \neq}$, Tania Cristina Leite de Sampaio e Spohr ${ }^{1 \neq}$ and Vivaldo Moura-Neto ${ }^{1,2,6 *}$

\begin{abstract}
${ }^{1}$ Instituto Estadual do Cérebro Paulo Niemeyer - Secretaria de Estado de Saúde, Rio de Janeiro, Brazil, ${ }^{2}$ Instituto de Ciências Biomédicas, Universidade Federal do Rio de Janeiro, Rio de Janeiro, Brazil, ${ }^{3}$ Center for Neuroscience and Cell Biology and Institute for Biomedical Imaging and Life Sciences Consortium, University of Coimbra, Coimbra, Portugal, ${ }^{4}$ Faculty of Medicine, University of Coimbra, Coimbra, Portugal, ${ }^{5}$ Programa de Pós-Graduação em Anatomia Patológica, Faculdade de Medicina, Universidade Federal do Rio de Janeiro, Rio de Janeiro, Brazil, ${ }^{6}$ Universidade do Grande Rio (Unigranrio), Duque de Caxias, Brazil, ${ }^{7}$ Centro de Cirurgia Experimental do Departamento de Cirurgia da Faculdade de Medicina, Universidade Federal do Rio de Janeiro, Rio de Janeiro, Brazil
\end{abstract}

In recent years, the functions of glial cells, namely, astrocytes and microglia, have gained prominence in several diseases of the central nervous system, especially in glioblastoma $(\mathrm{GB})$, the most malignant primary brain tumor that leads to poor clinical outcomes. Studies showed that microglial cells or astrocytes play a critical role in promoting GB growth. Based on the recent findings, the complex network of the interaction between microglial/astrocytes cells and GB may constitute a potential therapeutic target to overcome tumor malignancy. In the present review, we summarize the most important mechanisms and functions of the molecular factors involved in the microglia or astrocytes-GB interactions, which is particularly the alterations that occur in the cell's extracellular matrix and the cytoskeleton. We overview the cytokines, chemokines, neurotrophic, morphogenic, metabolic factors, and non-coding RNAs actions crucial to these interactions. We have also discussed the most recent studies regarding the mechanisms of transportation and communication between microglial/astrocytes - GB cells, namely through the ABC transporters or by extracellular vesicles. Lastly, we highlight the therapeutic challenges and improvements regarding the crosstalk between these glial cells and GB.

Keywords: glioblastoma, astrocytes, microglia, crosstalk, cytokines, molecular mechanisms, microenvironmental factors, communication mechanisms

\section{INTRODUCTION}

Glioblastoma (GB) is the most malignant primary tumor that affects the central nervous system (CNS) (Louis et al., 2016). Besides the conventional treatment to these tumors is complex, and based on surgery, radiotherapy, and chemotherapy with the gold-standard temozolomide (TMZ), the GB patient's survival rate remains about 15 months after diagnosis (Stupp et al., 2007, 2009). 
In addition, the poor efficacy of TMZ has led the scientific community to find new therapeutic strategies that could be used for effective GB treatment using new substances or FDAapproved drugs against gliomas (Balça-Silva et al., 2015; Matias et al., 2017a). However, most of these substances do not have the ability to cross the blood-brain barrier (BBB), the biggest challenge to the passage of chemotherapeutics to the brain (Dubois et al., 2014). This barrier not only is composed mostly of endothelial cells, pericytes, fibroblasts, neurons, and basal membranes but also receives support from glial cells, such as astrocytes and microglia (Dubois et al., 2014; Zhao et al., 2017). During glioma progression, the BBB is compromised that allows the entrance of immune cells from blood, which in turn, promotes neuroinflammation. However, these alterations induce the chemoattraction and activation of glial cells. In fact, microglial cells produce high levels of proinflammatory molecules, such as nitric oxide (NO) and tumor necrosis factor alpha (TNF- $\alpha$ ) which induce the BBB breakdown (Zhao et al., 2017). On the other hand, the tumor cells can induce the astrocytic activation by releasing interleukins (ILs), such as IL-1, and consequently disrupting the astrocyte-BBB junctions (Guan et al., 2018). Overall, these inflammatory alterations contribute to create an imbalance in the BBB function in the context of brain tumors like GB.

In fact, the mechanisms that support the GB's resistance ability have been recently discussed, and it is already known that GB heterogeneity is a crucial reason to that resistance, due to communication between tumor and tumor parenchyma entities (Hambardzumyan et al., 2016).

Among various cells of the tumor microenvironment (TME), among the glial cells, like astrocytes and the microglial cells, are the most common cellular entities that interact with the GB and, consequently, contribute to their tumor growth (Gieryng et al., 2017b; Roos et al., 2017; Roesch et al., 2018).

Several studies using GB patient biopsies and in vivo animal models showed that the tumor mass is composed of $30-50 \%$ of glioma-associated microglia/macrophages (GAMs) (Roggendorf et al., 1996; Olah et al., 2012; Carvalho da Fonseca et al., 2014; Garcia et al., 2014; Zhang et al., 2015). Tumor cells have the ability to evade immune cells by creating an immunosuppressive microenvironment by releasing immunosuppressive factors, such as cytokines, chemokines, neurotrophic, and morphogenic factors, among others (Roggendorf et al., 1996; Olah et al., 2012; Garcia et al., 2014; Zhang et al., 2015; da Fonseca et al., 2016). In GBs, microglial cells have been shown to have a protumor phenotype that is associated with the M2-like phenotype of macrophages due to its expression of specific factors, such as ILs, transforming growth factor beta 1 (TGF- $\beta 1$ ), monocyte chemoattractant protein (MCP-1), and prostaglandin E2 (PGE2) (Li and Graeber, 2012). On the other hand, GBs also induce alterations on astrocytes, turning them more reactive (Roessler et al., 1995; Guan et al., 2018). At the same time, the glial cells from TME also release factors that support the GB growth. Among those factors it has been previously demonstrated that $\mathrm{CD} 11 \mathrm{~b}+/ \mathrm{Cd} 45-$ microglial cells are located around the tumor and express arginase-1 (ARG-1), which in turn stimulates the tumor proliferation (Zhang et al., 2015). Moreover, GB establishes direct contact with astrocytes/microglial cells through extracellular vesicles (EVs). EVs can transport important molecules, such as miRNAs and cytokines, that will turn astrocytes more reactive and, at the same time, induce M2-like phenotype on microglial cells (van der Vos et al., 2016; Oushy et al., 2018).

In this regard, the manipulation of microglia/astrocytesGB crosstalk may be on the basis of many important and potential therapeutic strategies for the successful treatment of GB. Recently, it has been demonstrated that targeting microglial cells and astrocytes may be a potential tool for manipulating the GB growth (Ye et al., 2012; da Fonseca et al., 2016).

Taking this knowledge into account, many studies have recently focused on the identification of the principal targets and the most useful strategies to treat GB. In glioma-bearing mice, the blockage of CSF-1R, using the anti-CSF-1R antibody, known as Pexidartinib (PLX3397), is observed to significantly decrease tumor infiltration of GAMs leading to a reduction of the tumor volume (Pyonteck et al., 2013).

In the following sections, we will describe the physiological, biochemical, and microenvironmental functions of microglia/astrocytes with GB cells interaction, the molecular mechanisms underlying their crosstalk, their impact on tumor malignancy, and how this can be translated in a therapeutic purpose.

\section{GLIOMAS: A DEADLY THREAT}

Among the glial cells, astrocytes and oligodendrocyte precursor cells (OPCs), which can differentiate into oligodendrocytes, are derived from stem-like radial glial cells in ventricular and subventricular zones during embryogenesis. Recently, one of the hypotheses to explain the origin of gliomas has been supported by several genetic and epigenetic mutations that occur on normal astrocytes, oligodendrocytes, and OPCs. Consequently, these mutations can give rise to gliomas. Among the most known are the oligodendrogliomas, oligoastrocytomas, or astrocytomas (Rycaj and Tang, 2015; Zong et al., 2015).

Gliomas are the most common primary malignant tumors of CNS in adults (Thakkar et al., 2014), 50\% of which is GB. According to the World Health Organization's (WHO) classification, they are ranked as the most malignant astrocytoma (Grade IV) (Ringertz, 1950; Paff et al., 2014; Urbańska et al., 2014; Louis et al., 2016) and will form the basis of this review.

Glioblastomas are mainly characterized by nuclear atypia, cellular pleomorphism, mitotic activity, diffuse growth pattern, microvascular proliferation, and/or necrosis, which constitute the main diagnostic features (Faria et al., 2006; Urbańska et al., 2014). These characteristics are the result of the genomic instability and the deregulation of several molecular signaling pathways that culminate in a high resistance to chemotherapy (Louis et al., 2016; Wirsching and Weller, 2016). The therapeutic approaches to GB treatment are highly aggressive, like surgery, radiotherapy, and chemotherapy with TMZ, the gold-standard treatment. However, only $5 \%$ of the patients survive $>5$ years (Ohgaki and Kleihues, 2007; Ostrom et al., 2014). 
In this vein, the low survival of GB patients is due to the mechanisms of resistance and high heterogeneity (Stupp et al., 2007). This heterogeneity seems to be an indispensable key for tumor progression, resistance, metastasis, and tumor recurrence (Patel et al., 2014; Wang et al., 2017). Moreover, two types of tumor heterogeneity coexist: intrinsic and extrinsic. Currently, it is known that the intrinsic heterogeneity present in tumors is defined by the presence of cell niches with distinct phenotypic characteristics. It is believed by the scientific community that the presence of a subpopulation known as cancer stem-like cells (CSCs) is responsible for this heterogeneity. The maintenance of the different phenotypes also depends on the interaction with the microenvironment. These interactions are derived from the activation of several pathways through membrane receptors and their ligands, such as growth factors and cytokines as the epidermal growth factor receptor (EGFR) or IL-6, respectively. In addition, these factors are essential for the recruitment of parenchymal cells, such as endothelial cells, astrocytes, and microglia, that ultimately infiltrate to the tumor, helping tumor progression, which is referred to as extrinsic heterogeneity (Wang et al., 2009; Fonseca et al., 2012; Patel et al., 2014).

The conventional treatments contribute to the maintenance of GB heterogeneity. The main goals of surgery are to establish a pathological diagnosis, relieve mass effect, and achieve a gross total resection to facilitate adjuvant therapy (Moiyadi and Shetty, 2012). Removing of 98\%, or even more, of the tumor mass identified in magnetic resonance imaging (MRI) conduct to a statistically significant increase in patient survival rate (Miller et al., 1988). Regarding radiotherapy, it is well known that it contributes to the proliferation of GSCs (Bao et al., 2006). In fact, the radiation has been associated to an increased number of non-tumor cells, such as reactive astrocytes and microglia/macrophages in the tumor bulk (Hwang et al., 2006; Tabatabaei et al., 2017). Recently, high levels of MCP-1, IL-8, and macrophage inflammatory protein-1 alpha (MIP-1a), which are associated with inflammatory response (Tabatabaei et al., 2017), were observed in irradiated GB tissues. Our group already showed that the TMZ does not significantly affect the glial cells proliferation, as well as microglial cells and astrocytes (Kahn et al., 2012). Overall, surgery, radiotherapy, and/or chemotherapy are still the conventional therapeutic arms against GB, although they are quite ineffective.

Altogether, the factors mentioned above, the intrinsic heterogeneity of this neoplasia, the invasive capability, the absence of a total tumor resection, and the enormous alterations in the TME, which represent the extrinsic heterogeneity, contribute to tumor resistance (Abou-Antoun et al., 2017; Arbab et al., 2017; Roos et al., 2017).

Regarding TME, multiple factors are known to influence the tumor aggressiveness, mainly hypoxia, the hypervascularity in the microenvironment, and the crosstalk between GBs and GAMs or astrocytes (Markovic et al., 2005; da Fonseca et al., 2016; Hambardzumyan et al., 2016; Audia et al., 2017; Matias et al., 2017b; Guan et al., 2018). In this sense, the next section of the review will explore the role played by microglial and astrocytes cells in modulating GB malignancy and therapy resistance.

\section{MICROGLIA AND ASTROCYTES' ROLE IN GLIOBLASTOMA MALIGNANCY}

This might be one of the most exploited topics regarding TME, and it plays the main role during tumor progression, influencing cancer invasion, aggressiveness, and resistance (Pitt et al., 2016). In particular, GBs are recognized as heterogeneous tumors due to the presence of different subpopulations within the tumor mass, some of them with distinct origin of neoplastic cells. This heterogeneity is established by the interaction between tumor cells and "stroma cells," such as astrocytes and microglial cells, which are normally responsible for the brain homeostasis (Hambardzumyan et al., 2016; Gieryng et al., 2017b; Roos et al., 2017; Roesch et al., 2018). Nevertheless, in the context of the tumor, the glial and immune cells do not recognize the cancer cells as an intruder, and so do not fight them. So how do the tumor cells evade the immune system?

According to the histopathological and flow cytometry studies, the human and mice glioma biopsies are composed of $30-40 \%$ of microglial cells (Graeber et al., 2002; Garcia et al., 2014; Huszthy et al., 2015; Annovazzi et al., 2018). Microglia is called the glial cell; however, their origin is distinct from the other glial cells. The microglial cells are derived from the precursors of yolk sac during early embryogenesis instead of radial glia-like astrocytes (Del Rio Ortega, 1932; Ginhoux et al., 2013).

In fact, the microglial cells are considered the immune cells of the CNS (Del Rio Ortega, 1932; Ginhoux et al., 2013) since they share macrophages characteristic of acquiring different phenotypes depending on the pathological stimuli. For many years, it has been considered that the M1/M2 polarization that occurs in macrophages are also present in microglial cells. These phenotypes have been associated with the distinct production of pro-inflammatory or anti-inflammatory cytokines (Hambardzumyan et al., 2016; Lisi et al., 2017). Although these cells have a notable plasticity, and some studies showed that microglial cells could converge between M1/M2-like phenotype (Hambardzumyan et al., 2016; Lisi et al., 2017; Matias et al., 2018), they can also display different protein expressions of both M1- and M2-like phenotypes at the same time (Lisi et al., 2014; Gabrusiewicz et al., 2016; Ransohoff and El Khoury, 2016). The expression of pro-inflammatory cytokines, such as IL-2 and 12, interferon gamma (IFN- $\gamma$ ), and TNF- $\alpha$, has been associated with the M1-like phenotype. Meanwhile, the presence of IL-10 and TNF- $\beta$ is apparently associated to the M2like phenotype (Roessler et al., 1995; Hambardzumyan et al., 2016; Lisi et al., 2017). However, other proteins have been associated with the M1/M2 polarization of microglial cells. For example, regarding the microglial cells with M1-like phenotype, the increased levels of cytokines and ILs, such as TNF- $\alpha$ and IL-12, IL-23, and IL-1 $\beta$, as well as NO, were normally observed. In parallel, the M2-like phenotype not only presents high expression of IL-10, but also increased levels of ARG1 , stress inducible protein (STI-1), and inducible NO synthase 
(iNOS) (da Fonseca et al., 2016; Hambardzumyan et al., 2016; Annovazzi et al., 2018). Also, GAMs can express some markers, such as cluster of differentiation 163 (CD163), a marker highly specific for the M2-like phenotype (Lau et al., 2004), and CD68 that is expressed by both M1 and M2 macrophages (Holness and Simmons, 1993). Recently, it has been described that the transmembrane protein 119 (TMEM119) can also be used as a specific microglia marker (Satoh et al., 2016).

In the case of GBs, glioma cells are able to suppress the microglial M1-like phenotype and induce an M2 antiinflammatory phenotype through the above-mentioned cytokines and chemokines, which in turn induce microglial cells to release different factors that will stimulate the tumor growth (Hambardzumyan et al., 2016; Lisi et al., 2017). Moreover, the analysis of brain slices from a rat model of glioma using two-color time-lapse fluorescence microscopy showed that glioma cells induce microglia motility (Juliano et al., 2018). The transcriptome analysis of GBs showed upregulation of genes that are involved in the invasion capability and immunosuppression (Mieczkowski et al., 2015; Gieryng et al., 2017a).

In fact, the immunosuppressive microenvironment in GB occurs in various circumstances, which include the action of the GAMs and myeloid-derived suppressor cells (MDSCs) (Chang et al., 2016; Gieryng et al., 2017a). In the case of GBs, glioma cells are able to stimulate GAMs to produce immunosuppressive molecules, such as IL-10, metalloproteinases (MMPs), chemokines as monocyte chemotactic protein-1 (CCL2), and ARG-1, that stimulate the tumor growth (Chang et al., 2016; Zhang I. et al., 2016; Gieryng et al., 2017b; Lisi et al., 2017). Moreover, the presence of microglial M2-like phenotype has been associated with the aggressiveness and poor prognosis in GB patients (Mieczkowski et al., 2015; Iglesia et al., 2016; Gieryng et al., 2017a). Recently, it has been shown that CCL2 released by GB and GAMs acts as a chemoattractant to $\mathrm{C}-\mathrm{C}$ chemokine receptor type 2 (CCR2) + Ly-6C + MDSC (Chang et al., 2016). Moreover, MDSCs have the ability to release important cytokines, to name a few, the TGF- $\beta$ and IL10, among others, inside solid tumors, acting as immunosuppressants and promoting tumor growth. In this sense, inhibiting MDSCs function has been shown to promote antitumor immune responses (Zhang et al., 2018).

Moreover, tumor-directed cytotoxic T lymphocytes function is also regulated by immune checkpoints, such as programmed death (PD-1) receptor and their ligands PD-L1 and PD-L2 (DiDomenico et al., 2018). Specifically, PD-L1 is highly expressed in tumors, including gliomas. PD-L1 functions through its interaction with correspondent receptor PD-1 in the activated $\mathrm{T}$ cells. From this interaction results an inhibitory response. In this sense, increased expression of PD-L1 in GB patients has been correlated with poor survival of those receiving vaccine immunotherapy (DiDomenico et al., 2018). On the other hand, GAMs also release PD-L1 and, consequently, block the T cells through PD-1/PD-L1 signaling (Preusser et al., 2015).

There are different types of glial cells with different origins and ontogenies, for example, the astrocytes, as previously mentioned. In fact, other studies have shown that tumor cells can manipulate the behavior of astrocytes; by releasing a variety of factors, such as IL-10 and interferon beta (IFN- $\beta$ ), can also stimulate the anti-inflammatory phenotype of these cells (Guan et al., 2018). Recently, a study demonstrated that depending on the subpopulation of astrocytes submitted to the same oncogenic mutation (oncogenic TRP mutations), different types of gliomas could arise. For instance, the transformed glial fibrillary acidic protein (GFAP)-positive astrocytes induced anaplastic astrocytomas (WHO grade III and IV), while the transformed glutamate/L-aspartate transporter (GLAST)-positive astrocytes formed low-grade astrocytomas (WHO grade I) (Irvin et al., 2017).

Thus, as described above, microglia and astrocytes appear to be involved in various mechanisms connected to tumor growth. Here, we will describe recent discoveries about the factors that manipulate or may be involved in the interaction between tumor cells and entities from TME, such as microglia and astrocytes.

\section{The Multiple Factors Involved in Microglia/Astrocytes-Glioblastoma Interactions}

There are several factors implicated in the microglia/astrocytesGB crosstalk. Among them, alterations on extracellular matrix (ECM) components, cytoskeletal rearrangements, the cytokines, the chemokines, the neurotrophic and morphogenic factors, the metabolic factors, and the non-coding RNAs regulation are the most important ones and will be described in detail in the "The multiple factors involved in microglia/astrocytesglioblastoma interactions" section. The factors involved in microglia/astrocytes-GB interactions are represented in Figure $\mathbf{1 .}$

\section{Extracellular Matrix and Cytoskeletal Modulation During Microglia Polarization With M1/M2-Like Phenotype and Reactive Astrocytes}

During the inflammation process, there occur ECM and cytoskeleton rearrangements in TME. It has been shown that microglial cells are recruited to GBs by acquiring invasive and migration abilities (Hambardzumyan et al., 2016; Wang et al., 2017). Microglia migration and invasion capacity depend on their M1/M2 polarization. In IL-4-treated microglial cells, a higher migratory capacity through lower lamellipodia and extension of membrane ruffles was observed, and it accompanied a reduction of cell adhesion compared to lipopolysaccharides (LPS)-stimulated microglial cells (Lively and Schlichter, 2013).

Indeed, the process of changing microglia cytoskeletal occurs through the reorganization of microtubules involving the tubulin $\mathrm{B}$ cofactor (TBCB), which confers different microglia phenotypes, as described above (Fanarraga et al., 2009).

In parallel, recent studies have shown altered effects in the contraction of actin filaments on microglia functions. Microglial cells acquire a phagocytic phenotype through triggering receptor expressed on myeloid cells 2 (TREM2) engagement, and consequently, the F-actin rearrangements occur (Forabosco et al., 2013).

Specifically, the reduction of the actin filament is related to cellular senescence resulting in the decrease of proliferation, 


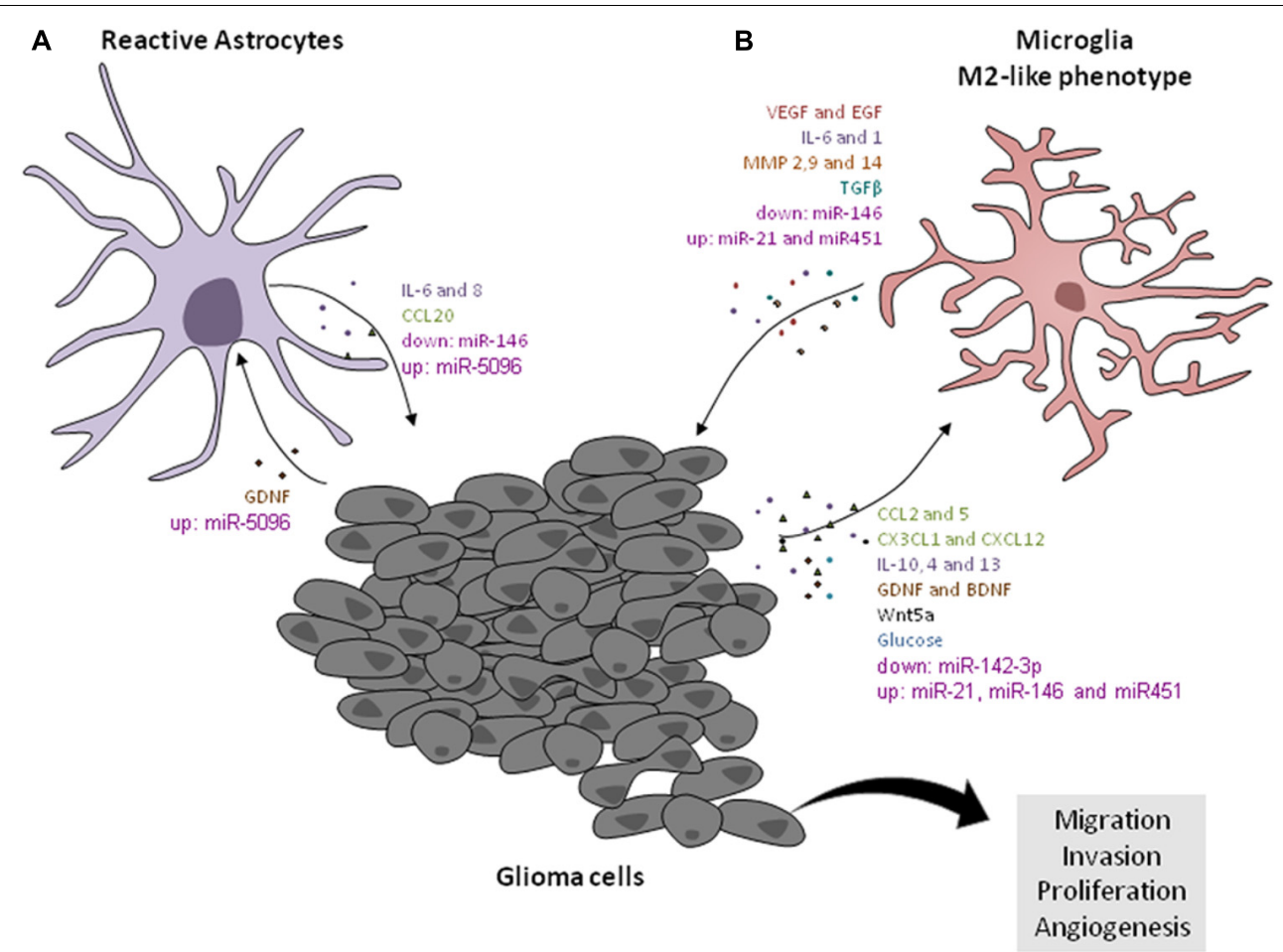

FIGURE 1 | Factors involved in microglial/astrocytic- GB cells crosstalk. (A) Astrocytic cells release IL-6 that contributes for tumor migration and invasion through the release of MMP14s by tumors cells. The astrocytic cells released CCL20, which increases HIF-1 $\alpha$ in GB cells via CCR6/NF-êB activation. GDNF released, by glioma cells, also promotes astrogliosis. GB cells transfer miR-5096 to astrocytes. (B) The GB cells release interleukins (IL10, IL4, and IL13) that induce the microglial cells to acquire M2-like phenotype. In turn, microglial cells secrete TGF- $\beta$ that stimulate the glioma growth. The invasion and migration of tumor cells are stimulated by the MMPs production by microglial cells. The tumor cells release the CCL2, which stimulates the release of IL-6 by microglia, and consequently induce the invasion of tumor cells. Also CCL5, produced by the GB cells, increases gene expression and function of the M2 markers ARG-1 and IL-10 on microglial cells. In addition, the GB cells express chemokine CX3CL1, which promotes the recruitment of microglial cells, through its receptor CX3CR1, and increases the expression of MMPs 2, 9, and 14, in the tumor cells, promoting tumor invasion. GDNF secreted from gliomas acts as chemoattractant for microglia. The IL-6 produced by microglia stimulates the expression of VEGF in tumor cells. Also, microglial cells release VEGF-A in tumor hypoxia areas. Immune brain cells express EGF in the tumor border, and thus stimulate invasion. Wnt5a released by glioma cells induces the M2-like phenotype in microglial cells through the increase of CX3CR1, CX43, CD163, and IBA-1. Glioma-released glucose induces the expression of GLUT5 in microglia and contributes to tumor growth. The downregulated levels of miR-142-3p are associated with M2-like phenotype in GAMs. IL-1 induces upregulation of miRNAs in gliomas involved in inflammation, such as miR-21 and miR-146. MiR-146 is downregulated in microglial cells and is associated with glioma growth. miRNA-21 and miRNA-451 are overexpressed in GB and are transferred to microglial cells.

migration, and phagocytosis associated to microglia events, as well as the M2 polarization (Uhlemann et al., 2016).

In addition to the cytoskeletal changes, ECM proteins also participate in this regulation. Xia et al. (2016) showed that tenascin-C (TNC) produced by GB cells could modulate the phenotype of microglial cells. In fact, the TNC knockdown, in GB xenografts, showed that major histocompatibility complex (MHC) class $\mathrm{II}^{+} /$ionized calcium binding adaptor

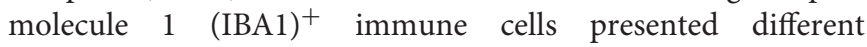
morphology involving fewer extensions. These alterations represent some activated amoeboid-like microglia in the center of the tumor mass compared to control GB xenografts, which presents a ramified microglia, a typical phenotype that is also observed in normal brain tissue (Xia et al., 2016).

Moreover, Ellert-Miklaszewska et al. (2016) demonstrated that osteopontin and lactadherin are released by GB cells and induce the M2-like phenotype on microglial cells by transforming those cells into amoeboid, ultimately increasing their ARG-1 levels. Together, these authors also observed that osteopontin and lactadherin derived from GB cells activate integrin/FAK/PI3K signaling pathway on microglial cells, promoting the rearrangements of the actin cytoskeleton, and consequently inducing the migration of the microglial cells (Ellert-Miklaszewska et al., 2016).

Ultimately, the Fibulin-3 is an extracellular protein described to be released by GB cells, and its expression is associated with tumor invasiveness and proliferation. Besides, an in vivo study showed that in the core and border of fibulin-3-overexpressed GB occurs the activation of NF-KB in p65+ astrocytes and GB cells (Nandhu et al., 2017).

Therefore, ECM and cytoskeletal proteins may be related to the crosstalk between microglia/astrocytes and GB. However, how cytoskeletal changes occur (e.g., intermediate filaments) and what types of ECM proteins are involved (such as laminin and collagen) in this crosstalk needs to be better explored. 


\section{Cytokines}

Glioblastoma casts an anti-inflammatory cytokine profile by producing vascular endothelial growth factor (VEGF), IL-10 and IL-6, and TGF- $\beta$ (Jackson et al., 2011).

Transforming growth factor beta is a cytokine that has a dual and complex role in cancer progression, depending on the stage of tumorigenesis and cell type (Landskron et al., 2014). In early stages of tumorigenesis, TGF- $\beta$ is a strong inhibitor of astrocytes, epithelial, and immune cell proliferation, by promoting apoptosis and inhibiting cellcycle progression (Joseph et al., 2013; Landskron et al., 2014). This occurs mainly because of the down-regulation of $\mathrm{c}-\mathrm{Myc}$ and upregulation of cyclin-dependent kinase inhibitor (CKI) P21 (Malliri et al., 1996). However, in later stages, TGF- $\beta$ increases metastasis and tumor invasion by inducing glial-mesenchymal transition (GMT) (Morrison et al., 2013). Therefore, TGF- $\beta$ is a cytokine also involved in glioma initiation, migration, and infiltration (Derynck et al., 2001; Wick et al., 2001; Roberts and Wakefield, 2003).

Microglial cells secrete TGF- $\beta$, and its inhibition abrogates glioma growth (Wesolowska et al., 2008). Recently, Zhu et al. (2016) showed that TGF- $\beta$ levels were twofold higher in microglia treated with glioma-conditioned medium (G/MCM) when compared to that in glioma-conditioned medium (G/CM), which shows that glioma stimulates microglia to produce high levels of TGF- $\beta$ (Zhu et al., 2016).

In addition, ILs are one of the most important molecules that regulate the immune response in the brain, and one of the most studied is IL-10 (Lobo-Silva et al., 2016). GB suppresses the immune response through IL-10, which is able to downregulate the MHC II expression in microglia, impairing the proliferative response of T cells (Frei et al., 1994).

In this sense, IL-10 acts by downregulating pro-inflammatory cytokines in GAMs, such as IFN and TNF production (Fulton et al., 1998).

Together with the IL-4, IL-13, and glucocorticoid hormones, the IL-10 induces GAMs to acquire M2-like phenotype (Mantovani et al., 2002). GAMs have been related with the glioma progression (Ford et al., 1995; Badie and Schartner, 2000; Coniglio et al., 2012). Cai et al. (2015) identified six cytokine signatures among a group of glioma patients with poor survival prognosis. Additionally, the authors related those cytokines with the M2-like phenotype, such as high levels of mRNA encoding IL-10 and TGF- $\beta 1$, with the glioma progression (Cai et al., 2015). Altogether, it has been suggested that GAMs release MMPs related to tumor invasion, specifically the MMP-2 and membrane type-1 (MT1)-MMP (Osenkowski et al., 2004; Mayes et al., 2006).

Another cytokine highly regulated in GB samples is IL-6 (Tchirkov et al., 2001). It has been shown that CCL2, produced by tumor cells, increases IL-6 levels released by microglia, which are associated to GB invasiveness and growth in a TLR4-dependent manner (Goswami et al., 1998; Wang et al., 2009; Zhang et al., 2012; a Dzaye et al., 2016). During the tumor invasiveness, IL-6 levels released by microglia increase MMP-9 levels (Yeung et al., 2013).
Interleukin-6 is also responsible for inducing VEGF synthesis, and both cytokines are able to induce tumor angiogenesis (Cohen et al., 1996; Huang et al., 2004).

The pro-angiogenic cytokine, VEGF, has been correlated with a poor prognosis and GB recurrence (Turkowski et al., 2018). GBs are recognized as highly angiogenic tumors (Brem et al., 1972). Besides GBs, GAMs are also able to produce VEGF (Chen et al., 2014; Brandenburg et al., 2016). In fact, Osterberg et al. (2016) demonstrated that VEGF is expressed not only in glioma blood vessels but also in tumor areas enriched with CD14+/CD68+ immune cells. Moreover, they also observed that in glioma hypoxia areas, the GAMs are responsible for VEGF-A production (Osterberg et al., 2016). Interestingly, it has been described that the inhibition of VEGF together with angiopoietin-2 (Ang-2) induce the polarization of GAMs to M1-like phenotype, as well as increase mice survival and delay the tumor growth (Kloepper et al., 2016). On the other hand, a decrease in GAMs infiltration was observed, followed by augmentation of apoptosis and MHC expression in VEGF-overexpressing gliomas, suggesting a regulatory feedback mechanism (Turkowski et al., 2018).

Overall, microglial cells are not the only glial cells that release IL-6, astrocytes too expressed high amounts of IL-6, in particular when co-cultured with GB cell lines, contributing to tumor migration and invasion through the release of the active form of MMP-14 by GB cells (Chen W. et al., 2016).

In this manner, cytokines represent crucial factors involved in microglia/astrocytes-GB crosstalk as represented in Figure $\mathbf{1 .}$

\section{Chemokines}

The chemokines are highly expressed by microglia and astrocytes and are mainly important to their recruitment and activation in cancer (Hattermann and Mentlein, 2014; Laudati et al., 2017; Jin et al., 2018).

Chemokine axes, such as fractalkine (CX3CL1)/CX3CR1, $\mathrm{C}-\mathrm{X}-\mathrm{C}$ motif chemokine ligand 12 (CXCL12)/C-X-C chemokine receptor type 4 and 7(CXCR4/CXCR7), CCL2/CCR2, and CCL5/CCR5, are clearly involved in tumor progression (HeldFeindt et al., 2010; Hattermann and Mentlein, 2014; Laudati et al., 2017).

Glioma-associated microglia/macrophages are characterized by the expression of those chemokines or receptors (Hattermann et al., 2014). And if the expression of GAMs M2-markers is decreased, this significantly increases survival and suppresses the growth of established tumor (Pyonteck et al., 2013).

In the brain, the neurons and astrocytes produce CX3CL1, and the receptor is restricted to microglia (Ludwig and Mentlein, 2008; Ransohoff and El Khoury, 2016). The CX3CL1 expressed by GB cells induces the human GAMs recruitment through its receptor CX3CR1 and increases the expression of matrix MMPs 2, 9, and 14 in GAMs, which consequently promotes the tumor invasion (Held-Feindt et al., 2010; Carvalho da Fonseca and Badie, 2013; Ferrer et al., 2018). In humans, but not in rodent models, the prolonged average of survival time of glioma patients and the low infiltration of microglia is associated with the CX3CR1 gene (Liu et al., 2008; Rodero et al., 2008). 
In turn, CXCL12 is widely produced in gliomas and normal brain. In tumor areas with necrosis, angiogenesis, and invasion, the GSCs express mainly the CXCR4 (Hattermann and Mentlein, 2014). ALTS1C1 cells, a new murine glioma model, expressed a relatively high level of CXCL12 in vitro and in vivo. The inhibition of CXCL12 by a specific siRNA has reduced tumor infiltration, and the formed tumors had defined borders. In addition, the inhibition of CXCL12 synthesis reduced migration of GAMs toward hypoxia regions (Wang et al., 2012). Therefore, the alteration of CXCL12-concentration gradient could be an important approach for the tropism of GAMs toward hypoxia areas (Hattermann and Mentlein, 2014). In the last decade, several preclinical studies in glioma models have shown that the impairment of the CXCL12/CXCR4 signaling using specific antagonists reduces tumor growth, angiogenesis, and recurrence, suggesting that this approach represents a promising strategy for GB therapy (Tseng et al., 2011; Liu et al., 2014).

The CCL2 was firstly detected in glioma cell supernatants and confirmed to be a chemoattractant protein for immune cells in vitro (Yoshimura et al., 1989). The astrocytes and microglia are the main sources of CCL2 in CNS (Vakilian et al., 2017). In GBs, the CCL2 expression is correlated with GAMs by recruitment of regulatory $\mathrm{T}$ cells and MDSCs to increase GB growth (Hattermann and Mentlein, 2014; Chang et al., 2016). Specifically, the glioma growth is induced by the IL-6 levels, which are produced by microglial cells under stimulation of glioma-released CCL2 that acts upon CCR2 in microglia. The CCL2-CCR2-IL-6 pathway is considered a potential therapeutic target for gliomas (Zhang et al., 2012). In addition, an interesting study demonstrated that astrocytes enhance the invasion of CD133+ GSCs, providing a microenvironment rich in cytokines and chemokines, such as CCL2 (Rath et al., 2013).

In addition to the chemokines mentioned above, the amounts of CCL5 and CCR 5 expression are correlated with poor prognosis and average survival time of GB patients (Laudati et al., 2017). Moreover, GAMs produce CCL5 and, consequently, potentiate the regulation of neurofibromatosis type 1 (NF1), associated with a murine low-grade optic glioma growth (Solga et al., 2015). CCL5 produced by the GB cells acts by increasing its cell survival using CD44 as a receptor, to suppress programmed cell death (Pan et al., 2017). Interestingly, Laudati et al. (2017) found that maraviroc (MRV), a CCR5 blocker, reduced the M2-like markers ARG-1 and IL-10 levels and function. In addition, the inhibition of CCR5 was correlated with a significant decrease of microglia migration, provoked by the inhibition of PI3-AKT pathway (Laudati et al., 2017).

It is already known that astrocytes-GB interactions can occur through the CCLs and ILs. In hypoxic conditions, the astrocytereleased CCL20 increases hypoxia-inducible factor 1-alpha (HIF$1 \alpha)$ in GB cells via CCR6/nuclear factor kappa B (NF-кB) activation and, in turn, induces GB cells to adapt to hypoxia (Jin et al., 2018).

Taken together, the communication network established among gliomas cells with TAMs and astrocytes cooperates through the chemokines (Figure 1) to increase glioma growth and infiltration into brain parenchyma, contributing to poor patient survival, and therefore, blockage of these pathways could assist in better therapy options for these patients.

\section{Neurotrophic and Morphogenic Factors}

During the last few years, the neurotrophic factors (NTFs) have gained importance due to their function of not only growth, differentiation, and survival of both mature and developing neurons (Ku et al., 2013; Liu et al., 2013) but also in modulation of microglial cells and astrocytes activity (Tanaka et al., 2008; $\mathrm{Xu}$ et al., 2018). The NTFs could be divided into six families (Table 1).

Moreover, it has been reported that glial-derived neurotrophic factor (GDNF) receptors, namely, GFRa-1 and GFRa-2, are expressed by microglial cells (Honda et al., 1999; Rickert et al., 2014). Ku et al. (2013) showed that the GDNF secreted from gliomas acts as a chemoattractant for microglia. In this study, the authors showed that mice xenografts of glioma cells silenced to GDNF reduced the GAMs and generated smaller tumors. Additionally, the GDNF released by glioma cells also promotes astrogliosis; in spite of the downregulation of GDNF, they did not observe any differences in astrocytes that surrounded the tumor mass ( $\mathrm{Ku}$ et al., 2013). Besides that, GB, as well as microglial cells, secretes cytokine TGF- $\beta$, which is important to stimulate tumor cell invasion (Han et al., 2015; Kim et al., 2017). Furthermore, TGF- $\beta$ in the presence of oncolytic herpes simplex viruses (oHSV) plays an anti-inflammatory role during glioma progression by decreasing the percentage of immune cells $\left(\mathrm{CD} 45^{+} \mathrm{CD} 11 \mathrm{~b}^{+}\right)$and, consequently, reducing their NO synthase 2 (NOS2) and TNF- $\alpha$ mRNA and protein levels involved in M1-like phenotype on microglial cells (Han et al., 2015). On the other hand, GSCs become more invasive, thereby promoting glioma progression in response to the TGF- $\beta 1$ secreted by the $\mathrm{CD} 11 \mathrm{~b}^{+} \mathrm{F} 4 / 80^{+}$immune cell population (Ye et al., 2012).

Moreover, TGF- $\beta$ can be associated with the VEGF expression, which is important not only for tumor vascularization but also in the modulation of macrophages/microglial cells activity (Roy et al., 2015). Recently, it has been demonstrated that high levels of VEGF induce GB progression and a marked remodeling of the vascular structure accompanied by an important reduction of $\mathrm{IBA}^{+}$cells. However, less accumulation of $\mathrm{IBA}^{+}$cells at the perivascular niche induced a reduction of pro-angiogenic factors (such as VEGF) released, suggesting a possible regulatory feedback mechanism (Turkowski et al., 2018). The authors also suggested that during an anti-VEGF therapy and standard VEGF expression, the tumor might manipulate microglia/macrophages to collaborate in angiogenesis (Turkowski et al., 2018).

Other NTF, such as colony stimulating factor-1 (CSF-1) and EGF, are also important to microglia-GB crosstalk (Pyonteck et al., 2013; Komohara et al., 2016; Kim et al., 2017). CSF1 acts as an oncogene by inducing gliomagenesis. Moreover, it was observed that the periphery of tumor mass of high-grade gliomas presents a minority population of GAMs that express ARG1 and CD206, typical markers for M2 polarization (De et al., 2016). Further, the $\mathrm{IBA}^{+}{ }^{+}$and $\mathrm{CD} 163^{+}$immune brain cells express EGF in the tumor border and thus stimulate the tumor cells to invade the parenchyma (Komohara et al., 2016; Hide et al., 2018). 
TABLE 1 | Neurotrophic and morphogenic factors involved in modulation of microglia/astrocytes phenotype in GB context.

\begin{tabular}{|c|c|c|c|c|}
\hline Family & & Type of factors & Hallmarks & References \\
\hline \multirow[t]{10}{*}{$\begin{array}{l}\text { Neurotrophic } \\
\text { factors }\end{array}$} & Neurotrophins & $\begin{array}{l}\text { Brain-derived neurotrophic } \\
\text { factor (BDNF) }\end{array}$ & $\begin{array}{l}\text { The BDNF derived from the brain-stimulated } \\
\text { microglial cells to produce IL-15 and } \\
\text { consequently increase NK cell infiltration and } \\
\text { activation, contributing to limit glioma expansion. }\end{array}$ & (Garofalo et al., 2017) \\
\hline & & Nerve growth factor (NGF) & $\begin{array}{l}\text { NGF is expressed by glioma cells. Microglia } \\
\text { expresses NGF receptors and when exposed to } \\
\text { NGF, acquire neuroprotective and } \\
\text { anti-inflammatory phenotype through modulation } \\
\text { of motility, phagocytosis, and degradation } \\
\text { pathways. No data in microglia-GB crosstalk. }\end{array}$ & $\begin{array}{l}\text { (Lawn et al., 2015; Rizzi } \\
\text { et al., 2018) }\end{array}$ \\
\hline & & Neurotrophin-3 (NT-3) & $\begin{array}{l}\text { NT-3 is important for the proliferation of brain } \\
\text { tumor-initiating cells. Microglial cells express } \\
\text { NT-3. No data in microglia-GB crosstalk. }\end{array}$ & $\begin{array}{l}\text { (Zhang et al., 2009; Forsyth } \\
\text { et al., 2014) }\end{array}$ \\
\hline & CNTF & $\begin{array}{l}\text { Ciliary neurotrophic factor } \\
\text { (CNTF) }\end{array}$ & $\begin{array}{l}\text { CNTF is synthesized and secreted by gliomas and } \\
\text { inhibits T-cell activation and microglia activation. } \\
\text { Microglia express CNTF receptor alpha (CNTFR } \alpha \text { ) } \\
\text { and its stimulation with CNTF induces COX2 } \\
\text { expression. CNT and CNTF } \alpha \text { are expressed by } \\
\text { astrocytes. No data in astrocytes-GB crosstalk. }\end{array}$ & $\begin{array}{l}\text { (Dallner et al., 2002; Lin } \\
\text { et al., 2009; Olah et al., } \\
\text { 2012) }\end{array}$ \\
\hline & GDNF & $\begin{array}{l}\text { Glial cell line-derived } \\
\text { neurotrophic factor (GDNF) }\end{array}$ & $\begin{array}{l}\text { Microglia and astrocytes express GFRa- } 1 \text { and } \\
\text { GFRa-2. Glioma-released GDNF acts as } \\
\text { chemoattractant for microglia and did not induce } \\
\text { astrogliosis. }\end{array}$ & (Ku et al., 2013) \\
\hline & Ephrins & Ephrin-B3 & $\begin{array}{l}\text { Ephrin-B3 is highly expressed in GBs. Astrocytes } \\
\text { express EphB3/EphA4 receptors. No data in } \\
\text { astrocytes-GB crosstalk. }\end{array}$ & $\begin{array}{l}\text { (Zhuang et al., 2011; Royet } \\
\text { et al., 2017) }\end{array}$ \\
\hline & EGF and TGF & $\begin{array}{l}\text { Transforming growth factor } \\
\text { beta }(\mathrm{TGF} \beta)\end{array}$ & $\begin{array}{l}\text { Reactive astrocytes have shown to secrete } \\
\text { TGF- } \beta \text {, which increases the proliferation and } \\
\text { invasion of tumor cell. }\end{array}$ & (Zhang et al., 2015) \\
\hline & & $\begin{array}{l}\text { Vascular endothelial growth } \\
\text { factor (VEGF) }\end{array}$ & $\begin{array}{l}\text { High levels of VEGF induce GB progression and a } \\
\text { marked remodeling of the vascular structure } \\
\text { accompanied with an important reduction of } \\
\text { microglial cells. }\end{array}$ & (Turkowski et al., 2018) \\
\hline & Others & $\begin{array}{l}\text { Macrophage colony-stimulating } \\
\text { factor (M-CSF) }\end{array}$ & $\begin{array}{l}\text { M-CSF [also named colony-stimulating factor } 1 \\
\text { (CSF-1)] promotes the upregulation of several M2 } \\
\text { markers and thereby actively contribute to the } \\
\text { M2-like GAM polarization. }\end{array}$ & (Komohara et al., 2008) \\
\hline & & $\begin{array}{l}\text { Granulocyte-macrophage } \\
\text { colony-stimulating factor } \\
\text { (GM-CSF) }\end{array}$ & $\begin{array}{l}\text { Microglia and astrocytes express GM-CSF } \\
\text { receptor, GM-CSF induces an inflammatory } \\
\text { response through IL-1 } \beta \text {, TNF } \alpha, \text { IL-10, and IL-6 } \\
\text { increased levels. GM-CSF is secreted by glioma } \\
\text { cells and induces GAM (IBA1+ cells) invasion. }\end{array}$ & $\begin{array}{l}\text { (Sielska et al., 2013; Nicol } \\
\text { et al., 2018) }\end{array}$ \\
\hline \multirow[t]{3}{*}{$\begin{array}{l}\text { Morphogenic } \\
\text { factors }\end{array}$} & Hedgehog & Sonic Hedgehog (Shh) & $\begin{array}{l}\text { Reactive astrocytes-released Shh drives } \\
\text { proliferation of IBA1+ immune cells } \\
\text { (microglia/macrophages). LPS-treated microglial } \\
\text { cells induce Shh expression. GB also secrete } \\
\text { Shh. No data in microglia/astrocytes-GB } \\
\text { crosstalk. }\end{array}$ & $\begin{array}{l}\text { (Pitter et al., 2014; Rimkus } \\
\text { et al., 2016; Lee et al., } \\
\text { 2017) }\end{array}$ \\
\hline & $\begin{array}{l}\text { Wingless-type MMTV } \\
\text { integration site }\end{array}$ & Wnt5a & $\begin{array}{l}\text { GB-released Wnt5a increase infiltration of the } \\
\text { immune cells (microglia). No data in } \\
\text { astrocytes-GB crosstalk. }\end{array}$ & (Dijksterhuis et al., 2015) \\
\hline & family (Wnt) & Wnt3a & $\begin{array}{l}\text { Microglial cells and astrocytes express Frizzled } \\
\text { (FZD) and LRP } 5 / 6 \text { receptors. Wnt3a is highly } \\
\text { expressed in GB cells. No data in } \\
\text { microglia/astrocytes-GB crosstalk. }\end{array}$ & $\begin{array}{l}\text { (Halleskog et al., 2011; } \\
\text { Denysenko et al., 2016) }\end{array}$ \\
\hline
\end{tabular}

Moreover, brain-derived neurotrophic factor (BDNF) is a very interesting NTF in the tumor context. GAMs, stimulated by brain-released BDNF, induced IL-15 production and, consequently, increased NK cells' infiltration and activation, contributing to limit glioma expansion (Garofalo et al., 2017).

Nevertheless, the morphogenic factors also play important roles in microglia/astrocytes-glioma crosstalk, mainly, the 
wingless-type MMTV integration site family (WNT) and sonic hedgehog (SHH). During early embryogenesis, these two factors are crucial for proper development of the tissues and organs (Matias et al., 2017b; Carballo et al., 2018). However, these pathways are recapitulated and play crucial roles during tumor development. Moreover, its influence on the immune system has also been highlighted over the last few years (Matias et al., 2017b).

In the TME, it was demonstrated that SHH is important for controlling epithelial-mesenchymal transition (EMT) - through a paracrine and autocrine manner - the pathogenesis, and progression of tumors, such as brain and prostate cancers (Tzelepi et al., 2011; Islam et al., 2016; Ming et al., 2017). In case of brain tumors, a study showed that in SHH subgroup of medulloblastoma, the tumor-macrophages/microglial cells might contribute to tumor growth, which has already been suggested as a potential therapeutic approach (Margol et al., 2015). Besides, it is already known that GB could secrete SHH (Rimkus et al., 2016). Additionally, reactive astrocytes can secrete Shh, inducing the proliferation of microglia, oligodendrocyte transcription factor (OLIG2) positive progenitors, and astrocytes after a neurodegeneration process (Pitter et al., 2014). However, the role of SHH from the GB cells in microglia and astrocytes proliferation and activation remains unclear.

Besides, it has been observed that SHH also interacts with other signaling pathways normally activated in tumors, including brain tumors, such as TGF- $\beta$ and the canonical WNT pathway (Carballo et al., 2018). It has been suggested that the WNT components can also be regulators of microglia-GB interactions (Matias et al., 2018). Both microglial and astroglial cells express high levels of WNT and FRIZZLED (FZD) receptors and play major roles in the modulation of the inflammatory response and cellular mechanisms, such as proliferation, migration, and invasion (L'Episcopo et al., 2018).

It has been described that during the inflammatory response in different contexts, the canonical and non-canonical WNT signaling pathways - more specifically, WNT3a and WNT5a have a great relevance (Halleskog and Schulte, 2013; Silva-García et al., 2014; Suryawanshi et al., 2015; Chen K. et al., 2016). Recently, it was suggested that WNT5a plays a crucial role in the interaction of the tumor with microglia. In silico studies, using GB samples from the TCGA and immunohistochemistry of human biopsies (TMAs), have shown that gliomas have high expression of WNT5a and that this aberrant expression is associated with the presence of immune cells. Moreover, this study showed that different groups, according to WNT5a expression, have different gene patterns. The glioma groups with high expression of WNT5a presented high levels of CX3CR1, connexin 43 (CX43), CD163, and IBA-1, suggesting that the GBinfiltrating microglial cells are activated, which represent the M2like phenotype. In addition, signaling pathways associated with the inflammatory response, such as toll-like receptors (TLRs), were identified (Dijksterhuis et al., 2015). Furthermore, it has been suggested that microglia may be one of the signaling entities for breast cancer cell metastases in the brain, since the microglia of organotypic brain cultures produce high levels of Wnt5a, promoting the growth of breast cancer (Pukrop et al., 2010; Nayak et al., 2012).
The glioma microenvironment can promote the activation of reactive astrocytes characterized by high expression of GFAP and the glycoprotein podoplanin. Lu et al. (2016) showed that tumor-associated astrocytes (TAAs) exhibited high-migration and invasion capability through the induction of GMT by increasing vimentin and MMP levels, which are WNT target proteins. Moreover, they observed that $\mathrm{WNT} / \beta$-catenin signaling pathway is activated in TAAS, suggesting that glioma cells induce the activation of TAAS via WNT/ $\beta$-catenin signaling ( $\mathrm{Lu}$ et al., 2016).

Altogether, the NTFs and morphogenic factors may also influence the immune system in tumors and, therefore, could be potential targets for tumor therapies (Figure 1). This subject still needs to be further exploited to address the role of these molecules in this crosstalk.

\section{Metabolic Factors}

In the last decades, some studies tried to understand how the metabolism of the CNS cells behaves in different physiological context, such as inflammation and cancer.

All types of cells need vast amounts of adenosine triphosphate (ATP) to survive, including microglia and astrocytes (Davalos et al., 2005; Engl and Attwell, 2015; Jackson and Robinson, 2018). Depending on the oxygen conditions, cells can produce ATP by the conversion of glucose to pyruvate through the mitochondrial tricarboxylic acid cycle (TCA) and glycolysis. On the other hand, in the absence of oxygen (hypoxia), cells transform the pyruvate into lactate by anaerobic glycolysis (Orihuela et al., 2016; Ghosh et al., 2018). Therefore, the study of the metabolic alterations that occur in microglia and astrocytes can be important in understanding the microglia polarization of M1-M2 and the astrocytes reactivity that occurs in GB.

During the polarization of M1/M2-like phenotypes in microglial cells, some alterations occur in metabolic circuits and mitochondrial respiration (Orihuela et al., 2016). Microglia express different transporters for main metabolites, such as glucose, glutamine, and fatty acids (Ghosh et al., 2018). One of the proteins that regulate the independent transport of glucose in microglia, and also in tumor cells, is the family of glucose transporter (GLUT) (Sasaki et al., 2004). Sasaki et al. (2004) showed that the GAMs express GLUT5 in non-necrotic areas of the tumor. Moreover, the microglial cells, under glucose deprivation (GD), increase the secretion of IL-6 (Choi et al., 2015) as well as their phagocytic behavior (Churchward et al., 2018). Taking into account that IL-6 and phagocytosis have been associated to M1-like phenotype in microglia (Hambardzumyan et al., 2016), the downregulation of glucose levels in GB or even the inhibition of GLUT5 may be useful to induce M1 polarization in microglial cells and, consequently, reduce the tumor aggressiveness.

The energy potential of mitochondria and other organelles for the cellular energy production machinery is indisputable since it participates in different fronts by performing various actions. Among them are the control of cytosolic calcium $\left(\mathrm{Ca}^{2+}\right)$ levels, the control of apoptosis through the transition of pore permeabilization, the reduction-oxidation modulation (redox), 
and the production of reactive oxygen species (ROS) (Wallace, 2012).

The variation of the internal $\mathrm{Ca}^{2+}$ levels, the cellular stress, or the decrease in the number of copies of the mitochondrial DNA can cause alterations of the membrane potential. Normally, the absorption of $\mathrm{Ca}^{2+}$ by the membrane of the mitochondria inhibits apoptosis of the cells and also induces high levels of ROS, which consequently leads to neoplastic transformation of the cells. However, high levels of ROS induce cellular apoptosis and necrosis because of its cellular toxicity. The increase of $\mathrm{Ca}^{2+}$ levels occurs in the cytoplasm compartment, which induces activation of $\mathrm{Ca}^{2+}$ signaling pathways that regulate tumorigenesis and invasive tumor growth (Gupta et al., 2012; Wallace, 2012).

Recently, it has been under discussion that the metabolic alterations contribute to the aggressiveness of the tumors, through the dysregulation of mitochondrial and cytoplasmic enzymes, such as enzyme isocitrate dehydrogenase (IDH) (Al-Khallaf, 2017). Particularly in gliomas, the presence of mutations in this enzyme, which has been associated to better prognosis and survival, comparably to IDH wild-type, has been reported (Louis et al., 2016). Normally, IDH1 is present in the cytoplasm and interfere with the catalyzation of isocitrate (ICT) into $\alpha$-ketoglutarate $(\alpha-K G)$ to produce nicotinamide adenine dinucleotide phosphate (NADPH) from $\mathrm{NADP}^{+}$. Instead, IDH2 regulates the reverse reaction of $\alpha-\mathrm{KG}$ into ICT in mitochondria (Al-Khallaf, 2017).

However, the presence of the mutations, IDH1-R132 and IDH2-R172, causes the reduction of $\alpha-\mathrm{KG}$ and an increase of R2-hydroxyglutarate (2HG) levels, an oncometabolite that induces alterations on chromatin and histone methylation (Ward et al., 2010; Koivunen et al., 2012; Amankulor et al., 2017).

How the IDH mutations interfere/modulate the TME has also been addressed in the literature. For instance, a study using a cohort of 60 patients with gliomas with $I D H 1-R 132 \mathrm{H}$ mutation was performed to understand if the GAMs samples also have the IDH1-R132H mutation. The authors showed that a population of $\mathrm{CD}^{+} 8^{+}, \mathrm{IBA}^{+}$, and $\mathrm{CX} 3 \mathrm{CR} 1^{+} \mathrm{GAMs}$ samples also had the IDH1-R132H mutation (Zheng et al., 2012). Moreover, mice with IDH1-R132H mutation showed elevated 2HG and deoxyribonucleic acid (DNA) methylation, as well as reduced immunological characteristics, such as reduced number of microglial cells (Zhang X. et al., 2016; Amankulor et al., 2017).

However, the $I D H$ mutations might occur in a subgroup of GB. Turcan et al. (2012) showed that IDH1 mutation modulates the differentiation state by increasing the nestin levels in normal human astrocytes (NHAs). Moreover, these IDH1 mutant cells produce higher levels of 2-HG, which is normally observed in low-grade brain tumors. According to the literature, the $I D H$ mutation in cancer patients is associated with better prognostic and survival rate, suggesting that IDH could be a promising target to reduce the aggressiveness of GB by modulating the astrocytes activity (Turcan et al., 2012).

Thus, we hypothesize that alterations in TCA cycle and glycolysis can induce the impairment of aggressiveness of the tumor and pro-inflammatory response (Figure 1) and be visualized as a possible target to establish new therapeutic strategies to combat the gliomas.

\section{Microglia/Astrocytes and Glioblastoma: The Role Played by Non-coding RNAs}

It is well known that RNA biology plays an important role in the CNS where robust expression of non-coding RNAs (ncRNAs) has been found. The ncRNAs are widely defined as all types of RNA that cannot be translated into proteins due to the lack of openreading frames (ORFs). They can be small ncRNAs (snRNAs) and long ncRNAs (lncRNAs) (Qureshi and Mehler, 2012; Aprea and Calegari, 2015; Ji et al., 2015; Quan et al., 2017).

The microRNAs (miRNAs) are snRNAs capable of regulating gene expression in cancer cells and associated normal cells (Pitt et al., 2016). Their unique features include regulation of multiple targets, ability to be secreted into the extracellular space, and the communication linking capacity between tumor cells and the TME. Therefore, studying miRNAs concerning the complex interactions between the tumor cells and their microenvironment is necessary for understanding the tumor progression and, thus, the development of new therapeutic strategies (Kros et al., 2014; Kohlhapp et al., 2015; Li and Liu, 2016).

Interestingly, the dysregulation of miRNAs in GAMs has been shown to promote tumorigenesis. For instance, the miR155 is a well-known regulator of the immune response and is involved with the M1/M2 polarization of macrophages/microglia (Cardoso et al., 2012). In the same context, studies that induce the pro-inflammatory phenotype in cultured microglia using LPS demonstrated an increased expression of miR-155 and miR-146 and a decreased expression of miR-689 and miR-124, of which miR-124 was associated with microglia quiescence (Ponomarev et al., 2013; Caldeira et al., 2014; Cunha et al., 2016). Notably, miR-155 was discovered to be constantly downregulated in immune cells, thus promoting tumorigenesis (He et al., 2009).

Another miRNAs have been found to be downregulated within GAMs, including the miR-142-3p and miR-146b-5p (Xu et al., 2014; Zhang et al., 2017). Consequently, the downregulation of miR-146b-5p was found to promote tumor proliferation and invasion ability (Cai et al., 2015) while the downregulation of miR-142-3p is associated with M2-like phenotype in GAMs. In vivo study has shown that the administration of miR-142$3 p$ induced the polarization of GAMs into M1-like phenotype, and consequently, the GB growth was reduced and the median survival rate increased (Xu et al., 2014).

Elsewhere, IL-1-induced miRNAs involved in inflammation, such as miR-21 and miR-146, have been found to be upregulated in low-grade gliomas (Tili et al., 2011; Prabowo et al., 2015).

In line with the previous thoughts, characterization of miRNA at the TME border can help to improve prognosis in GB patients. A miRNA expression study conducted using samples from the surrounding tissue of GB mass showed that miR-338-3p, miR219-2-3p, miR-27b, miR-23b, and miR-219-5p were upregulated while miR-H18, miR-1246, miR-1181, miR-3195, miR-630, miR642b, and miR-3663-3p were downregulated in the tumor border. Subsequently, miR-338-3p, miR-219-5p, and miR-219-2-3p were correlated to oligodendrocyte differentiation. The number of oligodendrocyte lineage cells was high in the border where 
macrophages and microglia were also colocalized. Moreover, it was observed in tumor mass border that increased levels of EGF, heparin-binding EGF-like growth factor (HB-EGF), IL-1 $\beta$, and acidic fibroblast growth factor (FGF1) that correspond to the presence of OPCs and macrophages/microglia are responsible for inducing stem-like phenotype and resistance in GB cells (Hide et al., 2018; Figure 1).

Moreover, in GBs, many well-known miRNAs that are highly expressed (let-7a, miR-16, miR-21, miR-27a, miR-26a, miR93, miR19b, miR-320, miR-20, miR-15b, and miR-92) in the microvesicles are isolated from patients. In this sense, an analysis of miRNAs transference through GB-isolated EVs to microglial cells showed that microglia had taken up these EVs, which increased the levels of miR451/miR21 to 15-fold (van der Vos et al., 2016). This means that probably miRNAs that are overexpressed in GB can be transferred to microglial cells by EVs (Figure 2).

Parallel to this, microRNAs can also be transferred between different cells in the TME through the gap junctions. Astrocytes have been shown to form gap junctions with glioma cells (Zhang et al., 1999), which then can potentially assist in tumor invasion. This was demonstrated by a study that found out that the glioma invasion was reduced by the gap junctions formed between glioma cells, while glioma-astrocyte and astrocyte-astrocyte gap junctions promote glioma invasion, at least in part, by the gliomatransferred miR-5096 to astrocytes (Hong et al., 2015).

In addition to its function in microglial cells as described above, the miR-146 is also a negative regulator of astrocytemediated inflammation (Iyer et al., 2012). Upregulation of this miRNA has been correlated with a reduced expression of its target, the TNF receptor associated factor (TRAF6), which is involved in a number of seizures in glioma patients. This suggests that miR-146 could be involved in the epileptogenic focus surrounding the tumor (Prabowo et al., 2015).

These studies support the role played by non-coding RNAs in facilitating intercellular communication between immune cells and GB, although their precise contribution in modulating microglia/astrocytes activity in the context of GB still has to be fully elucidated.

\section{Mechanisms of Transportation and Communication Between Microglial/Astrocytes-Glioblastoma Cells}

In order to make possible the microglia/astrocytes-GB crosstalk, some important mechanisms of transportation and/or communication among those cells play an utmost role, to name a few, the ATP Binding Cassette transporters (ABC transporters) and the EVs. We will describe, below, in further detail, the most important mechanisms of transportation and communication among microglial/astrocytes-GB cells, and it is also summarized in Figure 2.

\section{ABC Transporters}

The ABC transporter proteins are a superfamily of proteins, located in biological membranes of most cells from varied species, whose role is the active transport of a wide range of substances, most notably the efflux of endo- and xenobiotics (Johnson and Chen, 2017). These transporters are overexpressed in many cancers, including gliomas, and are responsible for the effluxion of a varied repertoire of chemotherapeutic drugs from cancer cells. The 49 currently known human ABC transporters have been grouped into seven families, ranging from ABCA to ABCG, depending on their sequence homology (Begicevic and Falasca, 2017).

In glioma, the most relevant $\mathrm{ABC}$ transporter proteins are p-glycoprotein (ABCB1), MDR-associated protein-1 (ABCC1), and breast cancer resistance protein (ABCG2) (Quezada et al., 2011). Studies have shown that the ABCC1, ABCB1, and ABCA13 are correlated with the level of glioma aggressiveness, with these proteins being overexpressed in high-grade glioma compared to low-grade astrocytoma (de Faria et al., 2008; BalçaSilva et al., 2017a; Dréan et al., 2018).

Despite their role in cancer, the expression of the transporters mentioned above has been documented in other TME cells, mainly in capillary epithelial cells, which constitute BBB. However, there is much less information on brain parenchymal cells, such as microglia, oligodendrocytes, and astrocytes (Gibson et al., 2012). One study that sought to link immune modulators and expression of $\mathrm{ABC}$ transporters was conducted in a BV-2 mouse model for microglia function (Gibson et al., 2012). Resting microglia phenotype, in a non-diseased brain, was shown to express mRNAs for transporters ABCC1, ABCC4, ABCB1, and ABCG2 with comparatively low ABCC5. When in vitro activation of microglia was performed using LPS, the microglial cells had a profound change in transporter expression with $\mathrm{ABCC} 4, \mathrm{ABCB} 1$, and ABCG2 decreasing half-fold while ABCC1 and ABCC5 had a 140 and $210 \%$ increase, respectively (Gibson et al., 2012).

Another study to determine the effect of specific cytokines on transporters was carried out using IL- 6 and TNF- $\alpha$, two proinflammatory cytokines, which are also produced by activated microglia. In primary microglia cell cultures, administration of these cytokines elicited opposing effects on ABCB1 expression, inducing a slight decrease in its mRNA levels after IL-6 administration and a significant increase after TNF treatment at both the gene and protein levels (Shi et al., 2012).

Additional roles are emerging for $\mathrm{ABC}$ proteins during the interactions of cancer cells with TME entities. The transportation of molecules into the TME, such as signaling lipids with established roles in tumor biology (for instance, prostaglandins, leukotrienes, and sphingosine-1-phosphate or SIP), and that are known to have profound effects on immune cells (for instance, microglia/macrophages), have been shown to be ABC transporter substrates (Cole, 2014; Fletcher et al., 2016). This raises the question of whether $\mathrm{ABC}$ transporter can mediate the efflux of these molecules and how is it important in the context of cancer and, in particular, cell-cell communication of populations within the tumor mass. There are very few studies that have sought to unravel the role played by $\mathrm{ABC}$ transporters in the interactions between gliomas and microglia or astrocytes.

Comparative analysis of ABCG2 expression in primary astrocytes and GSCs showed that ABCG2 is only expressed in GSCs and not in normal astrocytes (Chen et al., 2017). 


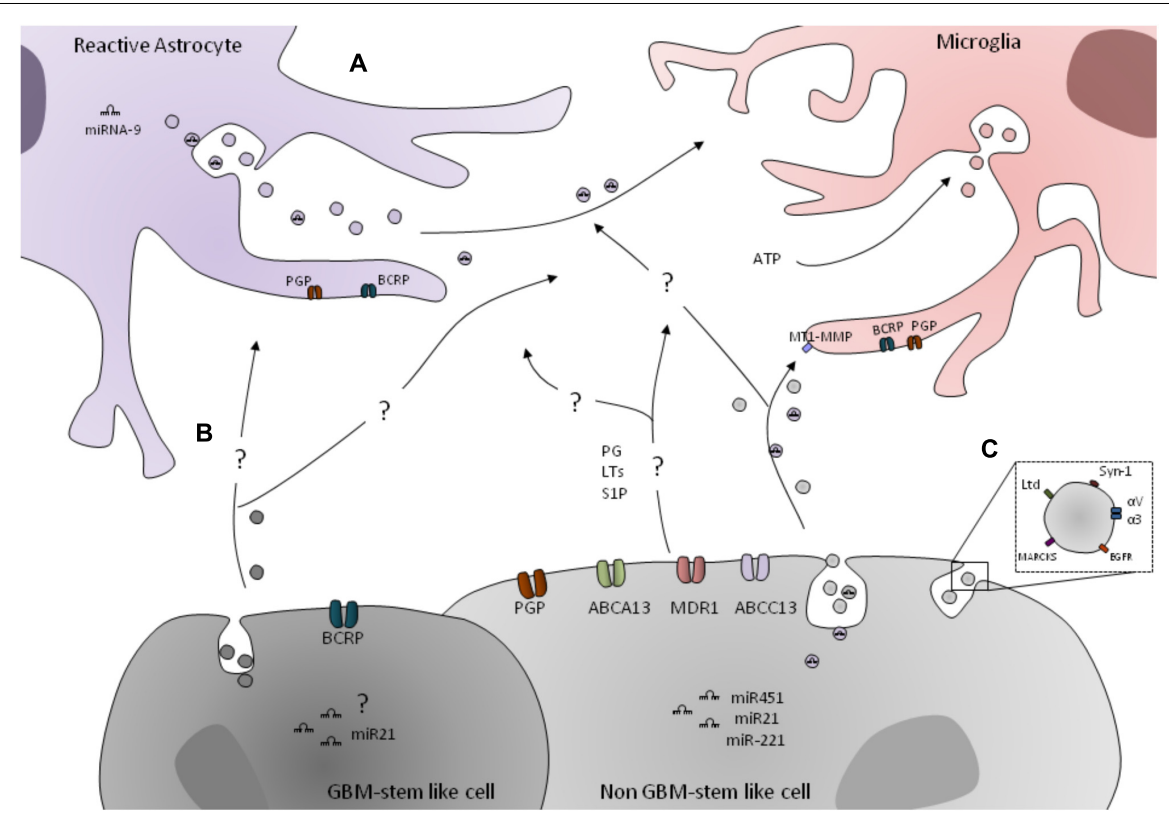

FIGURE 2 | Transportation mechanism involved in glial cells and GB crosstalk. (A) GB cells express several ABC transporters, such as ABCB1, ABCC1, ABCG2 and $A B C C 13$, and $A B C A 13$. GB cells express prostaglandins (PG), leukotrienes (LTS), and sphingosine-1-phosphate (S1P), which can be ABS transporters subtracts in microglial/astrocytic cells. The astrocytes and microglial cells express ABCG1 and ABCG2. Other mechanism of cell-cell communication is through the EVs, such as exosomes. GB miRNAs, namely the miR451, miR21, and miR-221, can be transferred through EVs to microglial cells. However, how can they be transferred to astrocytes is still unclear. Also, EVs are a mechanism for GB to induce MT1-MMP expression in GB-associated microglia. Moreover, extracellular ATP promotes microglia activation and induces the release of EVs in order to enable the communication between microenvironment cells. In fact, miR-9 released from Tat-stimulated astrocytes can be taken up by microglial cells, which result in their migratory phenotype. (B) ABCG2 is only expressed in GB-stem-like cells. Also, GB-released EVs can transport miRNAs, such as miR2. However, their role in astrocytic and microglial cells is not exploited. (C) Lactadherin (Lyd), syntenin-1(Syn-1), myristoylated alanine-rich C-kinase substrate (MARCKS), integrin alpha-V and alpha-3 ( $\alpha \mathrm{V}$ and $\alpha 3$ ), and EGFR can be detected in the membrane of GB-released EVs.

Recently, Dréan et al. (2018) performed a study to verify the expression of ABCA1, ABCA4, ABCA13, ABCC1, ABCC12, $\mathrm{ABCC} 13$, and $\mathrm{ABCG} 1$ in cohort of 51 newly diagnosed GB patients. They observed that GB overexpression of $\mathrm{ABCA} 13, \mathrm{ABCC}$, and $\mathrm{ABCC} 13$ are correlated with $\mathrm{GB}$ patient progression-free survival. Moreover, they also analyzed the $\mathrm{ABC}$ transporters in GB bulk cells, namely, astrocytes and microglial cells. They showed that ABCG1 and ABCG2 are mainly expressed by astrocytes while microglial cells have high expression of ABCG2 compared to the levels of ABCG1, but no ABCA13 expression was observed in these cells (Dréan et al., 2018). However, the differential relation and role of the $\mathrm{ABC}$ transporters in these cells is not completely elucidated (Figure 2).

So far, the experiments carried out have only shown effects of immune modulators secreted by activated immune cells like microglia/macrophages on the expression of $\mathrm{ABC}$ transporters. The overall effect of transporter upregulation or downregulation on the interactions between microglia or astrocytes and glioma, especially those effects that lead to tumor progression, are still under investigation.

\section{Extracellular Vesicles}

The cells can produce EVs that are constituted by a membranelimited vesicle that can be divided into three subclasses: apoptotic bodies, microvesicles (MVs), and exosomes (Ciregia et al., 2017).
The differences between all the three EV types are dependent and based on the origin and size of each one. The largest EVs, normally observed in cell death mechanisms, have a size that varies between this 1,000 and 5,000 $\mathrm{nm}$. The MVs derived from the external budding of the membrane can vary between 100 and $1,000 \mathrm{~nm}$; and finally, the smallest vesicles $(30-100 \mathrm{~nm})$ are the exosomes (Ciregia et al., 2017).

Among the EVs, the exosomes are the best described and enabled via communication between cells involved in many physiological processes, including its involvement in pathological condition by activating signaling pathways and changing components of the membrane and its neighbor cells (Abels and Breakefield, 2016; Ciregia et al., 2017).

Almost all the body fluids of humans [i.e., cerebrospinal fluid (CSF), blood plasma, saliva, or urine] have exosomes, so they are considered a promising diagnostic and prognostic biomarkers (Akers et al., 2015).

Regarding brain tumors, GB-derived MVs represent one of the mechanisms by which cancer cells can modulate the TME to a more permissive condition for growth and invasion (Dubois et al., 2014).

Our group has recently shown the plasticity of the stem-like cell state through the interconversion of more differentiated cells into a dedifferentiated state (Balça-Silva et al., 2017b). In fact, other authors mentioned that this plasticity could be mediated by MVs in in vivo conditions (Quesenberry et al., 2015). 
In parallel, the downregulation of mRNA expression levels of TIMP metallopeptidase inhibitor 1(TIMP1), TGF- $\beta$, and IL8 in exosomes is correlated with the survival of GB patients after a vaccination with dendritic cell-derived exosomes, which highlights a potential role of EVs in glioma immunotherapy (Muller et al., 2015).

Regarding the miRNAs' importance in gene regulation, it is also known in literature that several microRNAs are found to be encapsulated in EVs in the serum of glioma patients, which make them potential circulating biomarkers for early diagnosis, tumor staging, and prognosis. In fact, in serum-derived exosomes of GB patients and CSF-derived EVs, the miR-21 and miR-221 were shown to be highly enriched so that they may constitute potential relevant biomarkers (Akers et al., 2013; Yang et al., 2017).

Taking into account the crosstalk between GAMs in glioma, it is also important to highlight that recent studies showed that microglia-derived exosomes in the brain could be used as nanotherapeutic agents against glioma cells (Murgoci et al., 2018). In fact, extracellular ATP promotes microglia activation and induces the release of EVs, which can potentially mediate intercellular communication between microglia and the microenvironment (Drago et al., 2017). Furthermore, it was also demonstrated that the crosstalk between GB and astrocytes occurs through EVs. GB EV-treated NHAs had increased the expression of IFN- $\gamma$, ILs 12, 1A, 8, and 1B, chemokine CXCL10, and factor C5. Moreover, the conditioned medium of GB EVtreated NHAs induces the growth of GB cells. Thus, miR-9 released from Tat-stimulated astrocytes can be taken up by microglial cells, which result in their migratory phenotype. Therefore, glial crosstalk via miRNAs released from EVs play a crucial role mediating pathogenesis, which could eventually lead to the development of novel therapeutic strategies aimed at cushion neuropathogenesis (Yang et al., 2017).

\section{HOW TO MANIPULATE MICROGLIA/ASTROCYTES- GLIOBLASTOMA CROSSTALK}

There are many efforts to overcome the GB's resistance by finding and testing new compounds that can be used as therapeutic approaches. One of the main targets to these compounds are the neighbor entities of GBs, such as the microglia and astrocytes, since they have a great influence on the tumor progression (Hambardzumyan et al., 2016; Matias et al., 2018; Roesch et al., 2018).

We will present the most recent works that demonstrate to be potential therapeutic approaches to target microglia and astrocytes, which could turn off the immunosuppression observed in GBs and decrease their progression.

According to the literature, the tumor progression is facilitated by the immunosuppressive microenvironment created by GB and GAMS crosstalk (Hambardzumyan et al., 2016). In this regard, targeting microglial cells may be useful in manipulating GB growth, especially the GSCs (Ye et al., 2012; da Fonseca et al., 2016). Possibly, the therapeutic approach that can be used by chemoattractant receptors/ligands blockage to reduce GAMs recruitment, or even depleting or re-polarizing to enrich the pro-inflammatory M1-like GAMs, is still under discussion (Poon et al., 2017).

Among the therapeutic drugs targeting microglia in a preclinical model, the blockage of CSF-1R signaling in gliomabearing mice, through the anti-CSF-1R antibody Pexidartinib (PLX3397), resulted in a significant reduction tumor infiltration of GAMs and, consequently, a decrease in tumor volume, as well as an apparent increase of the survival time of treated mice (Pyonteck et al., 2013). However, later on, Butowski et al. (2016) showed that PLX3397 was well tolerated in patients and readily crossed the blood-tumor barrier but showed no efficacy.

Also, the CSF-R1 inhibitor BLZ945, in glioma-bearing mice, demonstrated reduced expression of M2-like markers in GAMs, which - after the administration of the insulin-like growth factor 1 (IGF-1) and phosphatidylinositol-4,5-bisphosphate 3-kinase (PI3K) antagonist - reduced the tumor progression, and an increase in the survival time of mice was observed (Coniglio et al., 2012). In agreement with that, Quail et al. (2016) concluded that the dual inhibition of IGF-1R/PI3K and CSF-1R significantly prolonged overall survival rate in recurrent glioma in mice.

The chemokines and their receptors are highly expressed in microglial cells, and they are extremely important to tumor progression (Zhao et al., 2015; Laudati et al., 2017; Jin et al., 2018). Thus, they may constitute a good target to decrease the microglia and tumor interaction. For that reason, many studies have been made to discover new inhibitors of chemokines receptors. Recently, it has been shown that the CCR5 blocker MRV was able to reduce the M2-like phenotype by reducing the ARG-1 and IL-10 proteins and promoting the upregulation of M1-like markers, such as NO and IL-1 $\beta$ in microglial cells treated in GB-conditioned medium (Laudati et al., 2017). The inhibition of the SDF-1 receptor (CXCR4) by using AMD3100 is another approach to target GAMs. Also, the inhibition of SDF in myeloid cells was performed using the Plerixafor in multiple myeloma and lymphoma, which constitutes a huge promise regarding glioma (Dillmann et al., 2009; Rios et al., 2016).

In the search to find an efficient anti-angiogenic therapy to treat $\mathrm{GB}$, it was recently demonstrated that the survival of GB-xenografts mice on the isolated anti-VEGF blockade was derived from the double blockade of Ang-2/increased VEGF. This dual blockade induced the reprogramming of GAMs from the pro-tumor M2-like phenotype toward the antitumor M1-like phenotype (Kloepper et al., 2016).

Moreover, another antagonist of CXCR4, the peptide $\mathrm{R}$, decreases the tumor mass of GB-xenotransplanted cells and reduces the CD11/CD68-positive cells in peritumoral zone of the tumor. In addition, the peptide R induces the M1-like phenotype in microglial cells by increasing the iNOS levels (Mercurio et al., 2016).

In parallel, AXL is highly expressed by GBs and microglia secrete the protein $\mathrm{S}$ (PROS1) responsible for phosphorylating AXL, which consequently induces the aggressiveness of GBs. Thus, Sadahiro et al. (2018) verified if the combination of a specific inhibitor of AXL (BGB324) with Nivolumab (antibody 
against PD-1) could be used for GB treatment. They showed increased survival in mice treated with BGB324 and Nivolumab. Further, in this study, the authors observed that protein $S$ (PROS1)/tyrosine-protein kinase (AXL) pathway is involved in extrinsic immune microenvironment by reduction of microglia infiltration after treatment (Sadahiro et al., 2018).

Moreover, in vitro and in vivo studies showed that the high expression of Nrp1 is correlated with the poor prognosis by inducing the proliferation and migration of GB cells. It has been shown that the Nrp1 is important to induce M2-like phenotype in microglia. Studies showed that the specific inhibitor of Nrp1 named EG00229 reduced tumor growth. These findings suggest that targeting Nrp1 could be a useful therapeutic approach for GBs since the EG00229 reduces Nrp1 expression and induces the M1 polarized phenotype on microglial cells, which consequently suppress the vascularization and proliferation of tumor cells (Miyauchi et al., 2016).

The phenolic compound, chlorogenic acid (CHA), has an anti-tumor effect in multiple malignant tumors, including GB. In vitro studies showed that CHA inhibited GB growth and induced apoptosis of GB cells. CHA promotes M1 polarization by increasing the levels of iNOS, MHC II, and $\mathrm{CD} 11 \mathrm{c}$ and, consequently, reduces the M2 polarized markers by decreasing ARG and CD206 levels. Besides, the CHA reduced the tumor size and increased the number of $\mathrm{CD} 11 \mathrm{c}^{+}$ M1 GAMs compared to CD206 ${ }^{+}$M2 GAMs in tumor tissue from mice orthotropic xenograft models of GB (Xue et al., 2017).

Histopathological studies demonstrated an increase of infiltrated microglia in chondroitin sulfate proteoglycan 4 (CSPG4), which is highly expressed in GB samples, co-expressing TNF- $\alpha$. Recently, regarding the new era of immunotherapy, Pellegatta et al. (2018) showed that CSPG4 can be targeted by CAR-T cells, promoting the control of tumor growth by inducing TNF- $\alpha$ expressed from microglial cells, leading to tumor cells death.
Together with microglial cells, astrocytes are also a crucial part of the TME cells that are involved in similar interactions with the tumor cells influencing its malignancy.

In this sense, it is known that hypoxic microenvironment maintains the malignant profile of GBs through the HIF- $1 \alpha$ expression. However, in a hypoxic microenvironment, there are still astrocytes, which can release high levels of CCL20 that, upon binding to the GB receptor CCR6, induce the expression of HIF-1 $\alpha$ (Jin et al., 2018). The authors noticed an increase in the tumor mass that was accompanied by a high vascularization and increased levels of HIF- $1 \alpha$ in mice injected with GB cells compared to CCR6-knockdown GB xenografts. These results suggest that, in a hypoxic microenvironment, GB cells growth is dependent on the CCL20 derived from astrocytes. Thus, the CCL20/CCR6 signaling could be a potential therapeutic target for GB treatment (Jin et al., 2018).

Some evidence support the idea that astrocytes can influence the tumor chemoresistance by protecting GB cells to TMZ or Vincristine (VCR) cytotoxicity by increasing the CX43. Therefore, it can be considered a potential target for the CX43-mediated GJCs between GB/astrocytic cells, and so the combination of the CX43 inhibitor with TMZ or VCR could be a successful therapy to GBs (Chen et al., 2015).

On the other hand, Hong et al. (2015) showed that the gap junctions play a role during glioma and astrocyte interactions by allowing the transference of miRs from glioma cells to astrocytes. So, the miR-4519 and miR-5096-transferred from GB to astrocytes through CX43 induce the pro-invasive phenotype in astrocytes (Hong et al., 2015). This evidence supports the idea that CXs and miRs may be a useful therapeutic target to decrease the interaction between astrocyte and GB and, consequently, decrease tumor progression.

As previously mentioned, the EVs are used by tumor cells as carriers to communicate with other cells from TME, such as astrocytes (Oushy et al., 2018). GB EVs modulate NHAs by increasing their migratory capability and inducing the cytokine production (as ILs 4, 10, and CCL2), which consequently

TABLE 2 | Microglial/astrocytic cells - therapeutic targets in GB.

\begin{tabular}{|c|c|c|c|c|}
\hline Therapy & Therapeutic target & Target cells & Study phase & References \\
\hline BLZ945 & $\begin{array}{l}\text { CSF-1R inhibition } \\
\text { combined with IGF-1R and } \\
\text { PI3K blockade }\end{array}$ & Microglia & Preclinical studies & Coniglio et al., 2012; Quail et al., 2016 \\
\hline Maraviroc (MRV) & CCR5 blockade & Microglia & Preclinical studies & Laudati et al., 2017 \\
\hline AMD3100 & $\begin{array}{l}\text { SDF-1 receptor (CXCR4) } \\
\text { inhibition }\end{array}$ & Microglia & Preclinical studies & Dillmann et al., 2009 \\
\hline BGB324 and Nivolumab & AXL and PD-1 inhibition & Microglia & Preclinical studies & Sadahiro et al., 2018 \\
\hline EG00229 & Nrp1 blockade & Microglia & Preclinical studies & Miyauchi et al., 2016 \\
\hline CART cells & CSPG4 inhibition & Microglia & Preclinical studies & Pellegatta et al., 2018 \\
\hline Chlorogenic acid (CHA) & Arg and CD206 & Microglia & Preclinical studies & Xue et al., 2017 \\
\hline
\end{tabular}


stimulate the tumor growth (Oushy et al., 2018). Therefore, finding a way to control the release of these GB EVs may be one possible strategy to decrease the tumor progression.

The principal studies previously mentioned regarding microglia/astrocytes GB crosstalk-therapeutic targets are summarized in Table 2.

\section{CONCLUSION AND FUTURE PERSPECTIVES}

During recent years, many efforts have been made to understand the heterogeneity of microglia/astrocytes. However, still little is known about the complex interaction and dynamics among microglia/astrocytes and tumor, such as GB, and how this crosstalk can influence tumor growth and patient's outcome. Nevertheless, to successfully improve GB patient survival, more in-depth knowledge is needed regarding the crosstalk between those TME cells.

In this review, we discussed the several factors and proteins already known that can modulate the activity of microglia or astrocytes during GB progression. Cytokines, chemokines, neurotrophic, and morphogenic factors can be associated with recruitment of tumor parenchyma cells, such as microglia and astrocytes, by the modulation of their phenotypes in order to influence tumor growth. In parallel, metabolic changes are known to be one of the more important engines for cell mechanisms, which include the cell proliferation and migration. In this regard, it is necessary to clarify the role of metabolites and enzymes of the cycle Krebs, as well as the glycolysis components during microglia/astrocytes-GB crosstalk. Also, the modulation of the cytoskeleton and ECM proteins is crucial for this crosstalk. However, more studies are needed to understand the underlying morphological changes during $\mathrm{M} 1$ and $\mathrm{M} 2$ polarization in microglia and astrocyte reactivity.

On the other hand, the miRNAs have been described as positive or negative regulators of this crosstalk, such as miR451/miR21 that are involved in microglia polarization into M1/M2-like phenotype. Thus, the identification of new miRNAs that can regulate this interaction is one of the main focus for future investigations.

The communication between microglial/astrocytes and GBs cells can be performed through the EVs. In fact, EVs can

\section{REFERENCES}

a Dzaye, O. D., Hu, F., Derkow, K., Haage, V., Euskirchen, P., Harms, C., et al. (2016). Glioma stem cells but not bulk glioma cells upregulate IL-6 secretion in microglia/brain macrophages via toll-like receptor 4 signaling. J. Neuropathol. Exp. Neurol. 75, 429-440. doi: 10.1093/jnen/nlw016

Abels, E. R., and Breakefield, X. O. (2016). Introduction to extracellular vesicles: biogenesis, RNA cargo selection, content, release, and uptake. Cell. Mol. Neurobiol. 36, 301-312. doi: 10.1007/s10571-016-0366-z

Abou-Antoun, T. J., Hale, J. S., Lathia, J. D., and Dombrowski, S. M. (2017). Brain cancer stem cells in adults and children: cell biology and therapeutic implications. Neurotherapeutics 14, 372-384. doi: 10.1007/s13311-0170524-0

Akers, J. C., Ramakrishnan, V., Kim, R., Phillips, S., Kaimal, V., Mao, Y., et al. (2015). miRNA contents of cerebrospinal fluid extracellular vesicles in participate in this interaction through the transport of several factors, such as miRNAs or even morphogenic factors, such as the Shh or Wnt. Also, the ABC transporters have a huge importance in GB resistance. Additionally, these transporters may also be involved in the transference of factors that modulate microglia/astrocytes behavior. Thus, it seems to us that the development of novel therapies, targeting factors/receptors that modulate the phenotype of microglial and astrocyte cells toward a proinflammatory behavior, may be a useful approach for GB patients. Table 2 represents some studies that are in clinical stages, and their results, such as PLX3397, have not been very promising. However, some studies have demonstrated the efficacy of compounds targeting membrane receptors on microglial cells, such as Plerixafor, peptide $\mathrm{R}$, and the combination of BGB324 with Nivolumab. Using the natural ability of the EVs as transporters, it may be possible to use them as drug delivery strategies, thus targeting the microglial and astrocytic cells.

In a clinical setting, it seems to be crucial to identify new potential targets in the microglia/astrocytes-GB crosstalk and, ultimately, develop a new range of therapeutic approaches, hopefully contributing in future to a better outcome for patients with an aggressive and deadly tumor, such as GB.

\section{AUTHOR CONTRIBUTIONS}

The review was conceptualized, written, edited, and critically evaluated by each of the authors. DM and JB-S had equal contribution for the literature search and article final preparation. The work was supervised by VF, TS, and VM-N. All authors read and approved the final submitted version of the manuscript.

\section{FUNDING}

This study was supported by the Brazilian Agencies Conselho Nacional de Desenvolvimento Científico e Tecnológico (CNPq), Coordenação de Aperfeiçoamento de Pessoal de Nível Superior (CAPES), Fundação de Amparo à Pesquisa do Rio de Janeiro (FAPERJ), and Pró-Saúde Associação Beneficente de Assistência Social e Hospitalar and Cancer Foundation.

glioblastoma patients. J. Neurooncol. 123, 205-216. doi: 10.1007/s11060-0151784-3

Akers, J. C., Ramakrishnan, V., Kim, R., Skog, J., Nakano, I., Pingle, S., et al. (2013). miR-21 in the extracellular vesicles (EVs) of cerebrospinal fluid (CSF): a platform for glioblastoma biomarker development. PLoS One 8:e78115. doi: 10.1371/journal.pone.0078115

Al-Khallaf, H. (2017). Isocitrate dehydrogenases in physiology and cancer: biochemical and molecular insight. Cell Biosci. 7:37. doi: 10.1186/s13578-0170165-3

Amankulor, N. M., Kim, Y., Arora, S., Kargl, J., Szulzewsky, F., Hanke, M., et al. (2017). Mutant IDH1 regulates the tumor-associated immune system in gliomas. Genes Dev. 31, 774-786. doi: 10.1101/gad.294991.116

Annovazzi, L., Mellai, M., Bovio, E., Mazzetti, S., Pollo, B., and Schiffer, D. (2018). Microglia immunophenotyping in gliomas. Oncol. Lett. 15, 998-1006. doi: 10.3892/ol.2017.7386 
Aprea, J., and Calegari, F. (2015). Long non-coding RNAs in corticogenesis: deciphering the non-coding code of the brain. EMBO J. 34, 2865-2884. doi: $10.15252 / \mathrm{embj} .201592655$

Arbab, A. S., Rashid, M. H., Angara, K., Borin, T. F., Lin, P.-C., Jain, M., et al. (2017). Major challenges and potential microenvironment-targeted therapies in glioblastoma. Int. J. Mol. Sci. 18, 1-19. doi: 10.3390/ijms18122732

Audia, A., Conroy, S., Glass, R., and Bhat, K. P. L. (2017). The impact of the tumor microenvironment on the properties of glioma stem-like cells. Front. Oncol. 7:143. doi: $10.3389 /$ fonc. 2017.00143

Badie, B., and Schartner, J. M. (2000). Flow cytometric characterization of tumorassociated macrophages in experimental gliomas. Neurosurgery 46, 957-961.

Balça-Silva, J., Matias, D., Do Carmo, A., Dubois, L. G., Gonçalves, A. C., Girão, H., et al. (2017a). Glioblastoma entities express subtle differences in molecular composition and response to treatment. Oncol. Rep. 38, 1341-1352. doi: 10.3892/or.2017.5799

Balça-Silva, J., Matias, D., Dubois, L. G., Carneiro, B., do Carmo, A., Girão, H., et al. (2017b). The expression of connexins and SOX2 reflects the plasticity of glioma stem-like cells. Transl. Oncol. 10, 555-569. doi: 10.1016/j.tranon.2017.04.005

Balça-Silva, J., Matias, D., do Carmo, A., Girão, H., Moura-Neto, V., SarmentoRibeiro, A. B., et al. (2015). Tamoxifen in combination with temozolomide induce a synergistic inhibition of PKC-pan in GBM cell lines. Biochim. Biophys. Acta 1850, 722-732. doi: 10.1016/j.bbagen.2014.12.022

Bao, S., Wu, Q., McLendon, R. E., Hao, Y., Shi, Q., Hjelmeland, A. B., et al. (2006). Glioma stem cells promote radioresistance by preferential activation of the DNA damage response. Nature 444, 756-760. doi: 10.1038/nature05236

Begicevic, R.-R., and Falasca, M. (2017). ABC transporters in cancer stem cells: beyond chemoresistance. Int. J. Mol. Sci. 18:E2362. doi: 10.3390/ijms18112362

Brandenburg, S., Müller, A., Turkowski, K., Radev, Y. T., Rot, S., Schmidt, C., et al. (2016). Resident microglia rather than peripheral macrophages promote vascularization in brain tumors and are source of alternative pro-angiogenic factors. Acta Neuropathol. 131, 365-378. doi: 10.1007/s00401-015-1529-6

Brem, S., Cotran, R., and Folkman, J. (1972). Tumor angiogenesis: a quantitative method for histologic grading. J. Natl. Cancer Inst. 48, 347-356.

Butowski, N., Colman, H., De Groot, J. F., Omuro, A. M., Nayak, L., Wen, P. Y., et al. (2016). Orally administered colony stimulating factor 1 receptor inhibitor PLX3397 in recurrent glioblastoma: an Ivy foundation early phase clinical trials consortium phase II study. Neuro. Oncol. 18, 557-564. doi: 10.1093/neuonc/ nov 245

Cai, J., Zhang, W., Yang, P., Wang, Y., Li, M., Zhang, C., et al. (2015). Identification of a 6-cytokine prognostic signature in patients with primary glioblastoma harboring M2 microglia/macrophage phenotype relevance. PLoS One 10:e0126022. doi: 10.1371/journal.pone.0126022

Caldeira, C., Oliveira, A. F., Cunha, C., Vaz, A. R., Falcão, A. S., Fernandes, A., et al. (2014). Microglia change from a reactive to an age-like phenotype with the time in culture. Front. Cell. Neurosci. 8:152. doi: 10.3389/fncel.2014.00152

Carballo, G. B., Honorato, J. R., de Lopes, G. P. F., and de Sampaio e Spohr, T. C. L. (2018). A highlight on Sonic hedgehog pathway. Cell Commun. Signal. 16:11. doi: 10.1186/s12964-018-0220-7

Cardoso, A. L., Guedes, J. R., Pereira, de Almeida, L., Pedroso, and de Lima, M. C. (2012). miR-155 modulates microglia-mediated immune response by down-regulating SOCS-1 and promoting cytokine and nitric oxide production. Immunology 135, 73-88. doi: 10.1111/j.1365-2567.2011.03514.x

Carvalho da Fonseca, A. C., and Badie, B. (2013). Microglia and macrophages in malignant gliomas: recent discoveries and implications for promising therapies. Clin. Dev. Immunol. 2013, 1-5. doi: 10.1155/2013/264124

Carvalho da Fonseca, A. C., Wang, H., Fan, H., Chen, X., Zhang, I., et al. (2014). Increased expression of stress inducible protein 1 in glioma-associated microglia/macrophages. J. Neuroimmunol. 274, 71-77. doi: 10.1016/j.jneuroim. 2014.06.021

Chang, A. L., Miska, J., Wainwright, D. A., Dey, M., Rivetta, C. V., $\mathrm{Yu}$, D., et al. (2016). CCL2 produced by the glioma microenvironment is essential for the recruitment of regulatory $\mathrm{T}$ cells and myeloid-derived suppressor cells. Cancer Res. 76, 5671-5682. doi: 10.1158/0008-5472.CAN16-0144

Chen, K., Fu, Q., Li, D., Wu, Y., Sun, S., and Zhang, X. (2016). Wnt3a suppresses Pseudomonas aeruginosa-induced inflammation and promotes bacterial killing in macrophages. Mol. Med. Rep. 13, 2439-2446. doi: 10.3892/mmr.2016. 4869
Chen, L., Shi, L., Wang, W., and Zhou, Y. (2017). ABCG2 downregulation in glioma stem cells enhances the therapeutic efficacy of demethoxycurcumin. Oncotarget 8, 43237-43247. doi: 10.18632/oncotarget.18018

Chen, W., Wang, D., Du, X., He, Y., Chen, S., Shao, Q., et al. (2015). Glioma cells escaped from cytotoxicity of temozolomide and vincristine by communicating with human astrocytes. Med. Oncol. 32:43. doi: 10.1007/s12032-015-0487-0

Chen, W., Xia, T., Wang, D., Huang, B., Zhao, P., Wang, J., et al. (2016). Human astrocytes secrete IL-6 to promote glioma migration and invasion through upregulation of cytomembrane MMP14. Oncotarget 7, 62425-62438. doi: 10.18632 /oncotarget.11515

Chen, X., Zhang, L., Zhang, I. Y., Liang, J., Wang, H., Ouyang, M., et al. (2014). RAGE expression in tumor-associated macrophages promotes angiogenesis in glioma. Cancer Res. 74, 7285-7297. doi: 10.1158/0008-5472.CAN-14-1240

Choi, J., Stradmann-Bellinghausen, B., Yakubov, E., Savaskan, N. E., and RégnierVigouroux, A. (2015). Glioblastoma cells induce differential glutamatergic gene expressions in human tumor-associated microglia/macrophages and monocyte-derived macrophages. Cancer Biol. Ther. 16, 1205-1213. doi: 10.1080/15384047.2015.1056406

Churchward, M. A., Tchir, D. R., and Todd, K. G. (2018). Microglial function during glucose deprivation: inflammatory and neuropsychiatric implications. Mol. Neurobiol. 55, 1477-1487. doi: 10.1007/s12035-017-0422-9

Ciregia, F., Urbani, A., and Palmisano, G. (2017). Extracellular vesicles in brain tumors and neurodegenerative diseases. Front. Mol. Neurosci. 10:276. doi: 10.3389/fnmol.2017.00276

Cohen, T., Nahari, D., Cerem, L. W., Neufeld, G., and Levi, B. Z. (1996). Interleukin 6 induces the expression of vascular endothelial growth factor. J. Biol. Chem. 271, 736-741. doi: 10.1074/jbc.271.2.736

Cole, S. P. C. (2014). Multidrug resistance protein 1 (MRP1, ABCC1), a "multitasking" ATP-binding cassette (ABC) transporter. J. Biol. Chem. 289, 30880-30888. doi: 10.1074/jbc.R114.609248

Coniglio, S., Eugenin, E., Dobrenis, K., Stanley, E. R., West, B. L., Symons, M. H., et al. (2012). Microglial stimulation of glioblastoma invasion involves epidermal growth factor receptor (EGFR) and colony stimulating factor 1 receptor (CSF-1R) signaling. Mol. Med. 18, 519-527. doi: 10.2119/molmed. 2011.00217

Cunha, C., Gomes, C., Vaz, A. R., and Brites, D. (2016). Exploring new inflammatory biomarkers and pathways during LPS-induced M1 polarization. Mediators Inflamm. 2016:6986175. doi: 10.1155/2016/6986175

da Fonseca, A. C. C., Amaral, R., Garcia, C., Geraldo, L. H., Matias, D., and Lima, F. R. S. (2016). Microglia in cancer: For good or for bad? Adv. Exp. Med. Biol. 949, 245-261. doi: 10.1007/978-3-319-40764-7_12

Dallner, C., Woods, A. G., Deller, T., Kirsch, M., and Hofmann, H.-D. (2002). CNTF and CNTF receptor alpha are constitutively expressed by astrocytes in the mouse brain. Glia 37, 374-378. doi: 10.1002/glia. 10048

Davalos, D., Grutzendler, J., Yang, G., Kim, J. V., Zuo, Y., Jung, S., et al. (2005). ATP mediates rapid microglial response to local brain injury in vivo. Nat. Neurosci. 8, 752-758. doi: $10.1038 / \mathrm{nn} 1472$

De, I., Steffen, M. D., Clark, P. A., Patros, C. J., Sokn, E., Bishop, S. M., et al. (2016). CSF1 overexpression promotes high-grade glioma formation without impacting the polarization status of glioma-associated microglia and macrophages. Cancer Res. 76, 2552-2560. doi: 10.1158/0008-5472.CAN-152386

de Faria, G. P., de Oliveira, J. A., de Oliveira, J. G. P., Romano, S., de, O., Neto, V. M., et al. (2008). Differences in the expression pattern of P-glycoprotein and MRP1 in low-grade and high-grade gliomas. Cancer Invest. 26, 883-889. doi: 10.1080/07357900801975264

Del Rio Ortega, P. (1932). "Microglia," in Cytology and Cellular Pathology of the Nervous System, ed. W. Penfield (New York, NY: Hafner).

Denysenko, T., Annovazzi, L., Cassoni, P., Melcarne, A., Mellai, M., and Schiffer, D. (2016). WNT/ $\beta$-catenin signaling pathway and downstream modulators in low- and high-grade glioma. Cancer Genomics Proteomics 13, 31-45. Available at: http://www.ncbi.nlm.nih.gov/pubmed/26708597

Derynck, R., Akhurst, R. J., and Balmain, A. (2001). TGF-beta signaling in tumor suppression and cancer progression. Nat. Genet. 29, 117-129. doi: 10.1038/ ng1001-117

DiDomenico, J., Lamano, J. B., Oyon, D., Li, Y., Veliceasa, D., Kaur, G., et al. (2018). The immune checkpoint protein $\mathrm{PD}-\mathrm{L} 1$ induces and maintains regulatory $\mathrm{T}$ 
cells in glioblastoma. Oncoimmunology 7:e1448329. doi: 10.1080/2162402X. 2018.1448329

Dijksterhuis, J. P., Arthofer, E., Marinescu, V. D., Nelander, S., Uhlén, M., Pontén, F., et al. (2015). High levels of WNT-5A in human glioma correlate with increased presence of tumor-associated microglia/monocytes. Exp. Cell Res. 339, 280-288. doi: 10.1016/j.yexcr.2015.10.022

Dillmann, F., Veldwijk, M. R., Laufs, S., Sperandio, M., Calandra, G., Wenz, F., et al. (2009). Plerixafor inhibits chemotaxis toward SDF-1 and CXCR4-mediated stroma contact in a dose-dependent manner resulting in increased susceptibility of BCR-ABL + cell to Imatinib and Nilotinib. Leuk. Lymphoma 50, 1676-1686. doi: $10.1080 / 10428190903150847$

Drago, F., Lombardi, M., Prada, I., Gabrielli, M., Joshi, P., Cojoc, D., et al. (2017). ATP modifies the proteome of extracellular vesicles released by microglia and influences their action on astrocytes. Front. Pharmacol. 8:910. doi: 10.3389/ fphar.2017.00910

Dréan, A., Rosenberg, S., Lejeune, F.-X., Goli, L., Nadaradjane, A. A., Guehennec, J., et al. (2018). ATP binding cassette (ABC) transporters: expression and clinical value in glioblastoma. J. Neurooncol. 138, 479-486. doi: 10.1007/s11060-0182819-3

Dubois, L. G., Campanati, L., Righy, C., D’Andrea-Meira, I., Spohr, T. C., PortoCarreiro, I., et al. (2014). Gliomas and the vascular fragility of the blood brain barrier. Front. Cell. Neurosci. 8:418. doi: 10.3389/fncel.2014.00418

Ellert-Miklaszewska, A., Wisniewski, P., Kijewska, M., Gajdanowicz, P., Pszczolkowska, D., Przanowski, P., et al. (2016). Tumour-processed osteopontin and lactadherin drive the protumorigenic reprogramming of microglia and glioma progression. Oncogene 35, 6366-6377. doi: 10.1038/onc.2016.55

Engl, E., and Attwell, D. (2015). Non-signalling energy use in the brain. J. Physiol. 593, 3417-3429. doi: 10.1113/jphysiol.2014.282517

Fanarraga, M. L., Villegas, J. C., Carranza, G., Castaño, R., and Zabala, J. C. (2009). Tubulin cofactor $\mathrm{B}$ regulates microtubule densities during microglia transition to the reactive states. Exp. Cell Res. 315, 535-541. doi: 10.1016/j.yexcr.2008. 10.045

Faria, J., Romão, L., Martins, S., Alves, T., Mendes, F. A., de Faria, G. P., et al. (2006). Interactive properties of human glioblastoma cells with brain neurons in culture and neuronal modulation of glial laminin organization. Differentiation 74, 562-572. doi: 10.1111/j.1432-0436.2006.00090.x

Ferrer, V. P., Moura Neto, V., and Mentlein, R. (2018). Glioma infiltration and extracellular matrix: key players and modulators. Glia 66, 1542-1565. doi: $10.1002 /$ glia. 23309

Fletcher, J. I., Williams, R. T., Henderson, M. J., Norris, M. D., and Haber, M. (2016). ABC transporters as mediators of drug resistance and contributors to cancer cell biology. Drug Resist. Updat. 26, 1-9. doi: 10.1016/j.drup.2016.03.001

Fonseca, A. C. C., da, Romão, L., Amaral, R. F., Assad Kahn, S., Lobo, D., et al. (2012). Microglial stress inducible protein 1 promotes proliferation and migration in human glioblastoma cells. Neuroscience 200, 130-141. doi: 10.1016/j.neuroscience.2011.10.025

Forabosco, P., Ramasamy, A., Trabzuni, D., Walker, R., Smith, C., Bras, J., et al. (2013). Insights into TREM2 biology by network analysis of human brain gene expression data. Neurobiol. Aging 34, 2699-2714. doi: 10.1016/j.neurobiolaging. 2013.05.001

Ford, A. L., Goodsall, A. L., Hickey, W. F., and Sedgwick, J. D. (1995). Normal adult ramified microglia separated from other central nervous system macrophages by flow cytometric sorting. Phenotypic differences defined and direct ex vivo antigen presentation to myelin basic protein-reactive $\mathrm{CD} 4^{+} \mathrm{T}$ cells compared. J. Immunol. 154, 4309-4321.

Forsyth, P. A., Krishna, N., Lawn, S., Valadez, J. G., Qu, X., Fenstermacher, D. A., et al. (2014). p75 neurotrophin receptor cleavage by $\alpha$ - and $\gamma$-secretases is required for neurotrophin-mediated proliferation of brain tumor-initiating cells. J. Biol. Chem. 289, 8067-8085. doi: 10.1074/jbc.M113.513762

Frei, K., Lins, H., Schwerdel, C., and Fontana, A. (1994). Antigen presentation in the central nervous system. The inhibitory effect of IL-10 on MHC class II expression and production of cytokines depends on the inducing signals and the type of cell analyzed. J. Immunol. 152, 2720-2728.

Fulton, S. A., Cross, J. V., Toossi, Z. T., and Boom, W. H. (1998). Regulation of interleukin-12 by interleukin-10, transforming growth factor-beta, tumor necrosis factor-alpha, and interferon-gamma in human monocytes infected with Mycobacterium tuberculosis H37Ra. J. Infect. Dis. 178, 1105-1114. doi: $10.1086 / 515698$
Gabrusiewicz, K., Rodriguez, B., Wei, J., Hashimoto, Y., Healy, L. M., Maiti, S. N., et al. (2016). Glioblastoma-infiltrated innate immune cells resemble M0 macrophage phenotype. JCI Insight 1:e85841. doi: 10.1172/jci.insight. 85841

Garcia, C., Dubois, L., Xavier, A., Geraldo, L., da Fonseca, A. C., Correia, A., et al. (2014). The orthotopic xenotransplant of human glioblastoma successfully recapitulates glioblastoma-microenvironment interactions in a non-immunosuppressed mouse model. BMC Cancer 14:923. doi: 10.1186/14712407-14-923

Garofalo, S., Porzia, A., Mainiero, F., Di Angelantonio, S., Cortese, B., Basilico, B., et al. (2017). Environmental stimuli shape microglial plasticity in glioma. eLife 6:e33415. doi: 10.7554/eLife.33415

Ghosh, S., Castillo, E., Frias, E. S., and Swanson, R. A. (2018). Bioenergetic regulation of microglia. Glia 66, 1200-1212. doi: 10.1002/glia.23271

Gibson, C. J., Hossain, M. M., Richardson, J. R., and Aleksunes, L. M. (2012). Inflammatory regulation of ATP binding cassette efflux transporter expression and function in microglia. J. Pharmacol. Exp. Ther. 343, 650-660. doi: 10.1124/ jpet.112.196543

Gieryng, A., Pszczolkowska, D., Bocian, K., Dabrowski, M., Rajan, W. D., Kloss, M., et al. (2017a). Immune microenvironment of experimental rat C6 gliomas resembles human glioblastomas. Sci. Rep. 7:17556. doi: 10.1038/s41598-01717752-w

Gieryng, A., Pszczolkowska, D., Walentynowicz, K. A., Rajan, W. D., and Kaminska, B. (2017b). Immune microenvironment of gliomas. Lab. Invest. 97, 498-518. doi: 10.1038/labinvest.2017.19

Ginhoux, F., Lim, S., Hoeffel, G., Low, D., and Huber, T. (2013). Origin and differentiation of microglia. Front. Cell. Neurosci. 7:45. doi: 10.3389/fncel.2013. 00045

Goswami, S., Gupta, A., and Sharma, S. K. (1998). Interleukin-6-mediated autocrine growth promotion in human glioblastoma multiforme cell line U87MG. J. Neurochem. 71, 1837-1845. doi: 10.1046/j.1471-4159.1998. 71051837.x

Graeber, M. B., Scheithauer, B. W., and Kreutzberg, G. W. (2002). Microglia in brain tumors. Glia 40, 252-259. doi: 10.1002/glia.10147

Guan, X., Hasan, M. N., Maniar, S., Jia, W., and Sun, D. (2018). Reactive astrocytes in glioblastoma multiforme. Mol. Neurobiol. doi: 10.1007/s12035-018-0880-8 [Epub ahead of print].

Gupta, S. C., Hevia, D., Patchva, S., Park, B., Koh, W., and Aggarwal, B. B. (2012). Upsides and downsides of reactive oxygen species for cancer: the roles of reactive oxygen species in tumorigenesis, prevention, and therapy. Antioxid. Redox Signal. 16, 1295-1322. doi: 10.1089/ars.2011.4414

Halleskog, C., Mulder, J., Dahlström, J., Mackie, K., Hortobágyi, T., Tanila, H., et al. (2011). WNT signaling in activated microglia is proinflammatory. Glia 59, 119-131. doi: 10.1002/glia.21081

Halleskog, C., and Schulte, G. (2013). WNT-3A and WNT-5A counteract lipopolysaccharide-induced pro-inflammatory changes in mouse primary microglia. J. Neurochem. 125, 803-808. doi: 10.1111/jnc.12250

Hambardzumyan, D., Gutmann, D. H., and Kettenmann, H. (2016). The role of microglia and macrophages in glioma maintenance and progression. Nat. Neurosci. 19, 20-27. doi: 10.1038/nn.4185

Han, J., Chen, X., Chu, J., Xu, B., Meisen, W. H., Chen, L., et al. (2015). TGF $\beta$ treatment enhances glioblastoma virotherapy by inhibiting the innate immune response. Cancer Res. 75, 5273-5282. doi: 10.1158/0008-5472.CAN-15-0894

Hattermann, K., and Mentlein, R. (2014). "“Para- and autocrine mediators in the glioma microenvironment," in Glioma Cell Biology, ed. M. R. Sedo (Dordrecht: Springer), 153-185.

Hattermann, K., Sebens, S., Helm, O., Schmitt, A. D., Mentlein, R., Mehdorn, H. M., et al. (2014). Chemokine expression profile of freshly isolated human glioblastoma-associated macrophages/microglia. Oncol. Rep. 32, 270-276. doi: 10.3892/or.2014.3214

He, M., Xu, Z., Ding, T., Kuang, D.-M., and Zheng, L. (2009). MicroRNA-155 regulates inflammatory cytokine production in tumor-associated macrophages via targeting C/EBP $\beta$. Cell. Mol. Immunol. 6, 343-352. doi: 10.1038/cmi. 2009.45

Held-Feindt, J., Hattermann, K., Müerköster, S. S., Wedderkopp, H., KnerlichLukoschus, F., Ungefroren, H., et al. (2010). CX3CR1 promotes recruitment of human glioma-infiltrating microglia/macrophages (GIMs). Exp. Cell Res. 316, 1553-1566. doi: 10.1016/j.yexcr.2010.02.018 
Hide, T., Komohara, Y., Miyasato, Y., Nakamura, H., Makino, K., Takeya, M., et al. (2018). Oligodendrocyte progenitor cells and macrophages/microglia produce glioma stem cell niches at the tumor border. EBioMedicine 30, 94-104. doi: 10.1016/j.ebiom.2018.02.024

Holness, C. L., and Simmons, D. L. (1993). Molecular cloning of CD68, a human macrophage marker related to lysosomal glycoproteins. Blood 81, 1607-1613.

Honda, S., Nakajima, K., Nakamura, Y., Imai, Y., and Kohsaka, S. (1999). Rat primary cultured microglia express glial cell line-derived neurotrophic factor receptors. Neurosci. Lett. 275, 203-206. doi: 10.1016/S0304-3940(99)00769-7

Hong, X., Sin, W. C., Harris, A. L., and Naus, C. C. (2015). Gap junctions modulate glioma invasion by direct transfer of microRNA. Oncotarget 6, 15566-15577. doi: 10.18632/oncotarget.3904

Huang, S.-P., Wu, M.-S., Shun, C.-T., Wang, H.-P., Lin, M.-T., Kuo, M.-L., et al. (2004). Interleukin-6 increases vascular endothelial growth factor and angiogenesis in gastric carcinoma. J. Biomed. Sci. 11, 517-527. doi: 10.1159/ 000077902

Huszthy, P. C., Sakariassen, P. Ø., Espedal, H., Brokstad, K. A., Bjerkvig, R., and Miletic, H. (2015). Engraftment of human glioblastoma cells in immunocompetent rats through acquired immunosuppression. PLoS One 10:e0136089. doi: 10.1371/journal.pone.0136089

Hwang, S.-Y., Jung, J.-S., Kim, T.-H., Lim, S.-J., Oh, E.-S., Kim, J.-Y., et al. (2006). Ionizing radiation induces astrocyte gliosis through microglia activation. Neurobiol. Dis. 21, 457-467. doi: 10.1016/j.nbd.2005.08.006

Iglesia, M. D., Parker, J. S., Hoadley, K. A., Serody, J. S., Perou, C. M., and Vincent, B. G. (2016). Genomic analysis of immune cell infiltrates across 11 tumor types. J. Natl. Cancer Inst. 108:djw144. doi: 10.1093/jnci/djw144

Irvin, D. M., McNeill, R. S., Bash, R. E., and Miller, C. R. (2017). Intrinsic astrocyte heterogeneity influences tumor growth in glioma mouse models. Brain Pathol. 27, 36-50. doi: 10.1111/bpa.12348

Islam, S. S., Mokhtari, R. B., Noman, A. S., Uddin, M., Rahman, M. Z., Azadi, M. A., et al. (2016). Sonic hedgehog (Shh) signaling promotes tumorigenicity and stemness via activation of epithelial-to-mesenchymal transition (EMT) in bladder cancer. Mol. Carcinog. 55, 537-551. doi: 10.1002/mc.22300

Iyer, A., Zurolo, E., Prabowo, A., Fluiter, K., Spliet, W. G. M., van Rijen, P. C., et al. (2012). MicroRNA-146a: a key regulator of astrocyte-mediated inflammatory response. PLoS One 7:e44789. doi: 10.1371/journal.pone.0044789

Jackson, C., Ruzevick, J., Phallen, J., Belcaid, Z., and Lim, M. (2011). Challenges in immunotherapy presented by the glioblastoma multiforme microenvironment. Clin. Dev. Immunol. 2011:732413. doi: 10.1155/2011/732413

Jackson, J. G., and Robinson, M. B. (2018). Regulation of mitochondrial dynamics in astrocytes: mechanisms, consequences, and unknowns. Glia 66, 1213-1234 doi: 10.1002/glia.23252

Ji, Z., Song, R., Regev, A., and Struhl, K. (2015). Many lncRNAs, 5’UTRs, and pseudogenes are translated and some are likely to express functional proteins. eLife 4:e08890. doi: 10.7554/eLife.08890

Jin, P., Shin, S.-H., Chun, Y.-S., Shin, H.-W., Shin, Y. J., Lee, Y., et al. (2018). Astrocyte-derived CCL20 reinforces HIF-1-mediated hypoxic responses in glioblastoma by stimulating the CCR6-NF- $\mathrm{B}$ signaling pathway. Oncogene 37, 3070-3087. doi: 10.1038/s41388-018-0182-7

Johnson, Z. L., and Chen, J. (2017). Structural basis of substrate recognition by the multidrug resistance protein MRP1. Cell 168, 1075.e9-1085.e9. doi: 10.1016/j. cell.2017.01.041

Joseph, J. V., Balasubramaniyan, V., Walenkamp, A., and Kruyt, F. A. E. (2013). TGF- $\beta$ as a therapeutic target in high grade gliomas - Promises and challenges. Biochem. Pharmacol. 85, 478-485. doi: 10.1016/j.bcp.2012.11.005

Juliano, J., Gil, O., Hawkins-Daarud, A., Noticewala, S., Rockne, R. C., Gallaher, J., et al. (2018). Comparative dynamics of microglial and glioma cell motility at the infiltrative margin of brain tumours. J. R. Soc. Interface 15:20170582. doi: 10.1098/rsif.2017.0582

Kahn, S. A., Biasoli, D., Garcia, C., Geraldo, L. H. M., Pontes, B., Sobrinho, M., et al. (2012). Equinatoxin II potentiates temozolomide- and etoposide-induced glioblastoma cell death. Curr. Top. Med. Chem. 12, 2082-2093. doi: 10.2174/ 156802612804910250

Kim, Y., Jeon, H., and Othmer, H. (2017). The role of the tumor microenvironment in glioblastoma: a mathematical model. IEEE Trans. Biomed. Eng. 64, 519-527. doi: 10.1109/TBME.2016.2637828

Kloepper, J., Riedemann, L., Amoozgar, Z., Seano, G., Susek, K., Yu, V., et al. (2016). Ang-2/VEGF bispecific antibody reprograms macrophages and resident microglia to anti-tumor phenotype and prolongs glioblastoma survival. Proc. Natl. Acad. Sci. U.S.A. 113, 4476-4481. doi: 10.1073/pnas.1525360113

Kohlhapp, F. J., Mitra, A. K., Lengyel, E., and Peter, M. E. (2015). MicroRNAs as mediators and communicators between cancer cells and the tumor microenvironment. Oncogene 34, 5857-5868. doi: 10.1038/onc.2015.89

Koivunen, P., Lee, S., Duncan, C. G., Lopez, G., Lu, G., Ramkissoon, S., et al. (2012). Transformation by the (R)-enantiomer of 2-hydroxyglutarate linked to EGLN activation. Nature 483, 484-488. doi: 10.1038/nature10898

Komohara, Y., Fujiwara, Y., Ohnishi, K., and Takeya, M. (2016). Tumor-associated macrophages: potential therapeutic targets for anti-cancer therapy. Adv. Drug Deliv. Rev. 99, 180-185. doi: 10.1016/j.addr.2015.11.009

Komohara, Y., Ohnishi, K., Kuratsu, J., and Takeya, M. (2008). Possible involvement of the M2 anti-inflammatory macrophage phenotype in growth of human gliomas. J. Pathol. 216, 15-24. doi: 10.1002/path.2370

Kros, J. M., Mustafa, D. M., Dekker, L. J. M., Sillevis Smitt, P. A. E., Luider, T. M., and Zheng, P.-P. (2014). Circulating glioma biomarkers. Neuro Oncol. 17, 343-360. doi: 10.1093/neuonc/nou207

Ku, M.-C., Wolf, S. A., Respondek, D., Matyash, V., Pohlmann, A., Waiczies, S. et al. (2013). GDNF mediates glioblastoma-induced microglia attraction but not astrogliosis. Acta Neuropathol. 125, 609-620. doi: 10.1007/s00401-0131079-8

Landskron, G., De la Fuente, M., Thuwajit, P., Thuwajit, C., and Hermoso, M. A. (2014). Chronic inflammation and cytokines in the tumor microenvironment. J. Immunol. Res. 2014:149185. doi: 10.1155/2014/149185

Lau, S. K., Chu, P. G., and Weiss, L. M. (2004). CD163: a specific marker of macrophages in paraffin-embedded tissue samples. Am. J. Clin. Pathol. 122, 794-801. doi: 10.1309/QHD6-YFN8-1KQX-UUH6

Laudati, E., Currò, D., Navarra, P., and Lisi, L. (2017). Blockade of CCR5 receptor prevents M2 microglia phenotype in a microglia-glioma paradigm. Neurochem. Int. 108, 100-108. doi: 10.1016/j.neuint.2017.03.002

Lawn, S., Krishna, N., Pisklakova, A., Qu, X., Fenstermacher, D. A., Fournier, M., et al. (2015). Neurotrophin signaling via TrkB and TrkC receptors promotes the growth of brain tumor-initiating cells. J. Biol. Chem. 290, 3814-3824. doi: 10.1074/jbc.M114.599373

Lee, J. H., Chung, Y. C., Bok, E., Lee, H., Huh, S. H., Lee, J. E., et al. (2017). Injury-stimulated Sonic hedgehog expression in microglia contributes to neuroinflammatory response in the MPTP model of Parkinson's disease. Biochem. Biophys. Res. Commun. 482, 980-986. doi: 10.1016/j.bbrc.2016.11.144 L’Episcopo, F., Tirolo, C., Serapide, M. F., Caniglia, S., Testa, N., Leggio, L., et al. (2018). Microglia polarization, gene-environment interactions and Wnt/ $\beta$-catenin signaling: emerging roles of glia-neuron and gliastem/neuroprogenitor crosstalk for dopaminergic neurorestoration in aged parkinsonian brain. Front. Aging Neurosci. 10:12. doi: 10.3389/fnagi.2018.00012

Li, Q., and Liu, Q. (2016). Noncoding RNAs in cancer immunology. Adv. Exp. Med. Biol. 927, 243-264. doi: 10.1007/978-981-10-1498-7_9

Li, W., and Graeber, M. B. (2012). The molecular profile of microglia under the influence of glioma. Neuro Oncol. 14, 958-978. doi: 10.1093/neuonc/nos116

Lin, H.-W., Jain, M. R., Li, H., and Levison, S. W. (2009). Ciliary neurotrophic factor (CNTF) plus soluble CNTF receptor $\alpha$ increases cyclooxygenase-2 expression, $\mathrm{PGE}_{2}$ release and interferon- $\gamma$-induced CD40 in murine microglia. J. Neuroinflammation 6:7. doi: 10.1186/1742-2094-6-7

Lisi, L., Ciotti, G. M. P., Braun, D., Kalinin, S., Currò, D., Dello Russo, C., et al. (2017). Expression of iNOS, CD163 and ARG-1 taken as M1 and M2 markers of microglial polarization in human glioblastoma and the surrounding normal parenchyma. Neurosci. Lett. 645, 106-112. doi: 10.1016/j.neulet.2017. 02.076

Lisi, L., Stigliano, E., Lauriola, L., Navarra, P., and Dello Russo, C. (2014). Proinflammatory-activated glioma cells induce a switch in microglial polarization and activation status, from a predominant M2b phenotype to a mixture of M1 and M2a/B polarized cells. ASN Neuro 6, 171-183. doi: 10.1042/ AN20130045

Liu, B., Chen, Q., Tian, D., Wu, L., Dong, H., Wang, J., et al. (2013). BMP4 reverses multidrug resistance through modulation of BCL-2 and GDNF in glioblastoma. Brain Res. 1507, 115-124. doi: 10.1016/j.brainres.2013.02.039

Liu, S.-C., Alomran, R., Chernikova, S. B., Lartey, F., Stafford, J., Jang, T., et al. (2014). Blockade of SDF-1 after irradiation inhibits tumor recurrences of autochthonous brain tumors in rats. Neuro Oncol. 16, 21-28. doi: 10.1093/ neuonc/not149 
Liu, S.-Y., Chang, L.-C., Pan, L.-F., Hung, Y.-J., Lee, C.-H., and Shieh, Y.-S. (2008). Clinicopathologic significance of tumor cell-lined vessel and microenvironment in oral squamous cell carcinoma. Oral Oncol. 44, 277-285. doi: 10.1016/j. oraloncology.2007.02.007

Lively, S., and Schlichter, L. C. (2013). The microglial activation state regulates migration and roles of matrix-dissolving enzymes for invasion. J. Neuroinflammation 10:75. doi: 10.1186/1742-2094-10-75

Lobo-Silva, D., Carriche, G. M., Castro, A. G., Roque, S., and Saraiva, M. (2016). Balancing the immune response in the brain: IL-10 and its regulation. J. Neuroinflammation 13:297. doi: 10.1186/s12974-016-0763-8

Louis, D. N., Perry, A., Reifenberger, G., von Deimling, A., Figarella-Branger, D., Cavenee, W. K., et al. (2016). The 2016 world health organization classification of tumors of the central nervous system: a summary. Acta Neuropathol. 131, 803-820. doi: 10.1007/s00401-016-1545-1

Lu, P., Wang, Y., Liu, X., Wang, H., Zhang, X., Wang, K., et al. (2016). Malignant gliomas induce and exploit astrocytic mesenchymal-like transition by activating canonical Wnt/ $\beta$-catenin signaling. Med. Oncol. 33:66. doi: 10.1007/s12032016-0778-0

Ludwig, A., and Mentlein, R. (2008). Glial cross-talk by transmembrane chemokines CX3CL1 and CXCL16. J. Neuroimmunol. 198, 92-97. doi: 10.1016/ j.jneuroim.2008.04.024

Malliri, A., Yeudall, W. A., Nikolic, M., Crouch, D. H., Parkinson, E. K., and Ozanne, B. (1996). Sensitivity to transforming growth factor beta 1-induced growth arrest is common in human squamous cell carcinoma cell lines: c-MYC down-regulation and p21waf1 induction are important early events. Cell Growth Differ. 7, 1291-1304.

Mantovani, A., Sozzani, S., Locati, M., Allavena, P., and Sica, A. (2002). Macrophage polarization: tumor-associated macrophages as a paradigm for polarized M2 mononuclear phagocytes. Trends Immunol. 23, 549-555. doi: 10.1016/S1471-4906(02)02302-5

Margol, A. S., Robison, N. J., Gnanachandran, J., Hung, L. T., Kennedy, R. J., Vali, M., et al. (2015). Tumor-associated macrophages in SHH subgroup of medulloblastomas. Clin. Cancer Res. 21, 1457-1465. doi: 10.1158/1078-0432. CCR-14-1144

Markovic, D. S., Glass, R., Synowitz, M., Rooijen, N., van, and Kettenmann, H. (2005). Microglia stimulate the invasiveness of glioma cells by increasing the activity of metalloprotease-2. J. Neuropathol. Exp. Neurol. 64, 754-762. doi: 10.1097/01.jnen.0000178445.33972.a9

Matias, D., Balça-Silva, J., Dubois, L. G., Pontes, B., Ferrer, V. P., Rosário, L., et al. (2017a). Dual treatment with shikonin and temozolomide reduces glioblastoma tumor growth, migration and glial-to-mesenchymal transition. Cell. Oncol. 40, 247-261. doi: 10.1007/s13402-017-0320-1

Matias, D., Dubois, L. G., Pontes, B., Rosário, L., Ferrer, V. P., Balça-Silva, J., et al. (2018). GBM-derived Wnt3a induces M2-like phenotype in microglial cells through Wnt/ $\beta$-catenin signaling. Mol. Neurobiol. doi: 10.1007/s12035018-1150-5 [Epub ahead of print].

Matias, D., Predes, D., Niemeyer Filho, P., Lopes, M. C., Abreu, J. G., Lima, F. R. S., et al. (2017b). Microglia-glioblastoma interactions: new role for Wnt signaling. Biochim. Biophys. Acta 1868, 333-340. doi: 10.1016/j.bbcan.2017.05.007

Mayes, D. A., Hu, Y., Teng, Y., Siegel, E., Wu, X., Panda, K., et al. (2006). PAX6 suppresses the invasiveness of glioblastoma cells and the expression of the matrix metalloproteinase-2 gene. Cancer Res. 66, 9809-9817. doi: 10.1158/ 0008-5472.CAN-05-3877

Mercurio, L., Ajmone-Cat, M. A., Cecchetti, S., Ricci, A., Bozzuto, G., Molinari, A., et al. (2016). Targeting CXCR4 by a selective peptide antagonist modulates tumor microenvironment and microglia reactivity in a human glioblastoma model. J. Exp. Clin. Cancer Res. 35:55. doi: 10.1186/s13046-016-0326-y

Mieczkowski, J., Kocyk, M., Nauman, P., Gabrusiewicz, K., Sielska, M., Przanowski, P., et al. (2015). Down-regulation of IKK $\beta$ expression in glioma-infiltrating microglia/macrophages is associated with defective inflammatory/immune gene responses in glioblastoma. Oncotarget 6, 33077-33090. doi: 10.18632/oncotarget.5310

Miller, D. H., Rudge, P., Johnson, G., Kendall, B. E., Macmanus, D. G., Moseley, I. F., et al. (1988). Serial gadolinium enhanced magnetic resonance imaging in multiple sclerosis. Brain 111(Pt 4), 927-939. doi: 10.1093/brain/111. 4.927

Ming, J., Sun, B., Li, Z., Lin, L., Meng, X., Han, B., et al. (2017). Aspirin inhibits the SHH/GLI1 signaling pathway and sensitizes malignant glioma cells to temozolomide therapy. Aging 9, 1233-1247. doi: 10.18632/aging. 101224

Miyauchi, J. T., Chen, D., Choi, M., Nissen, J. C., Shroyer, K. R., Djordevic, S., et al. (2016). Ablation of Neuropilin 1 from glioma-associated microglia and macrophages slows tumor progression. Oncotarget 7, 9801-9814. doi: 10.18632/ oncotarget.6877

Moiyadi, A., and Shetty, P. (2012). Perioperative outcomes following surgery for brain tumors: objective assessment and risk factor evaluation. J. Neurosci. Rural Pract. 3, 28-35. doi: 10.4103/0976-3147.91927

Morrison, C. D., Parvani, J. G., and Schiemann, W. P. (2013). The relevance of the TGF- $\beta$ Paradox to EMT-MET programs. Cancer Lett. 341, 30-40. doi: 10.1016/j.canlet.2013.02.048

Muller, L., Muller-Haegele, S., Mitsuhashi, M., Gooding, W., Okada, H., and Whiteside, T. L. (2015). Exosomes isolated from plasma of glioma patients enrolled in a vaccination trial reflect antitumor immune activity and might predict survival. Oncoimmunology 4:e1008347. doi: 10.1080/2162402X.2015. 1008347

Murgoci, A.-N., Cizkova, D., Majerova, P., Petrovova, E., Medvecky, L., Fournier, I., et al. (2018). Brain-cortex microglia-derived exosomes: nanoparticles for glioma therapy. ChemPhysChem. 19, 1205-1214. doi: 10.1002/cphc.2017 01198

Nandhu, M. S., Kwiatkowska, A., Bhaskaran, V., Hayes, J., Hu, B., and Viapiano, M. S. (2017). Tumor-derived fibulin-3 activates pro-invasive NF-кB signaling in glioblastoma cells and their microenvironment. Oncogene 36, 4875-4886. doi: 10.1038/onc.2017.109

Nayak, L., Lee, E. Q., and Wen, P. Y. (2012). Epidemiology of brain metastases. Curr. Oncol. Rep. 14, 48-54. doi: 10.1007/s11912-011-0203-y

Nicol, L. S. C., Thornton, P., Hatcher, J. P., Glover, C. P., Webster, C. I., Burrell, M., et al. (2018). Central inhibition of granulocyte-macrophage colony-stimulating factor is analgesic in experimental neuropathic pain. Pain 159, 550-559. doi: 10.1097/j.pain.0000000000001130

Ohgaki, H., and Kleihues, P. (2007). Genetic pathways to primary and secondary glioblastoma. Am. J. Pathol. 170, 1445-1453. doi: 10.2353/ajpath.2007.070011

Olah, M., Raj, D., Brouwer, N., De Haas, A. H., Eggen, B. J. L., Den Dunnen, W. F. A., et al. (2012). An optimized protocol for the acute isolation of human microglia from autopsy brain samples. Glia 60, 96-111. doi: 10.1002/glia. 21251

Orihuela, R., McPherson, C. A., and Harry, G. J. (2016). Microglial M1/M2 polarization and metabolic states. Br. J. Pharmacol. 173, 649-665. doi: 10.1111/ bph.13139

Osenkowski, P., Toth, M., and Fridman, R. (2004). Processing, shedding, and endocytosis of membrane type 1-matrix metalloproteinase (MT1-MMP). J. Cell. Physiol. 200, 2-10. doi: 10.1002/jcp.20064

Osterberg, N., Ferrara, N., Vacher, J., Gaedicke, S., Niedermann, G., Weyerbrock, A., et al. (2016). Decrease of VEGF-A in myeloid cells attenuates glioma progression and prolongs survival in an experimental glioma model. Neuro Oncol. 18, 939-949. doi: 10.1093/neuonc/now005

Ostrom, Q. T., Gittleman, H., Liao, P., Rouse, C., Chen, Y., Dowling, J., et al. (2014). CBTRUS statistical report: primary brain and central nervous system tumors diagnosed in the United States in 2007-2011. Neuro Oncol. 16(Suppl. 4), iv1-iv63. doi: 10.1093/neuonc/nou223

Oushy, S., Hellwinkel, J. E., Wang, M., Nguyen, G. J., Gunaydin, D., Harland, T. A., et al. (2018). Glioblastoma multiforme-derived extracellular vesicles drive normal astrocytes towards a tumour-enhancing phenotype. Philos. Trans. R. Soc. Lond. B. Biol. Sci. 373:20160477. doi: 10.1098/rstb.2016.0477

Paff, M., Alexandru-Abrams, D., Hsu, F. P. K., and Bota, D. A. (2014). The evolution of the EGFRvIII (rindopepimut) immunotherapy for glioblastoma multiforme patients. Hum. Vaccin. Immunother. 10, 3322-3331. doi: 10.4161/ 21645515.2014.983002

Pan, Y., Smithson, L. J., Ma, Y., Hambardzumyan, D., and Gutmann, D. H. (2017). Ccl5 establishes an autocrine high-grade glioma growth regulatory circuit critical for mesenchymal glioblastoma survival. Oncotarget 8, 32977-32989. doi: 10.18632/oncotarget.16516

Patel, A. P., Tirosh, I., Trombetta, J. J., Shalek, A. K., Gillespie, S. M., Wakimoto, H., et al. (2014). Single-cell RNA-seq highlights intratumoral heterogeneity in primary glioblastoma. Science 344, 1396-1401. doi: 10.1126/science.1254257

Pellegatta, S., Savoldo, B., Di Ianni, N., Corbetta, C., Chen, Y., Patané, M., et al. (2018). Constitutive and TNF $\alpha$-inducible expression of chondroitin sulfate 
proteoglycan 4 in glioblastoma and neurospheres: implications for CAR-T cell therapy. Sci. Transl. Med. 10:eaao2731. doi: 10.1126/scitranslmed.aao2731

Pitt, J. M., Marabelle, A., Eggermont, A., Soria, J.-C., Kroemer, G., and Zitvogel, L. (2016). Targeting the tumor microenvironment: removing obstruction to anticancer immune responses and immunotherapy. Ann. Oncol. 27, 1482-1492. doi: 10.1093/annonc/mdw168

Pitter, K. L., Tamagno, I., Feng, X., Ghosal, K., Amankulor, N., Holland, E. C., et al. (2014). The SHH/Gli pathway is reactivated in reactive glia and drives proliferation in response to neurodegeneration-induced lesions. Glia 62, 1595-1607. doi: 10.1002/glia.22702

Ponomarev, E. D., Veremeyko, T., and Weiner, H. L. (2013). MicroRNAs are universal regulators of differentiation, activation, and polarization of microglia and macrophages in normal and diseased CNS. Glia 61, 91-103. doi: 10.1002/ glia.22363

Poon, C. C., Sarkar, S., Yong, V. W., and Kelly, J. J. P. (2017). Glioblastomaassociated microglia and macrophages: targets for therapies to improve prognosis. Brain 140, 1548-1560. doi: 10.1093/brain/aww355

Prabowo, A. S., van Scheppingen, J., Iyer, A. M., Anink, J. J., Spliet, W. G. M., van Rijen, P. C., et al. (2015). Differential expression and clinical significance of three inflammation-related microRNAs in gangliogliomas. J. Neuroinflammation 12:97. doi: 10.1186/s12974-015-0315-7

Preusser, M., Berghoff, A. S., Wick, W., and Weller, M. (2015). Clinical Neuropathology mini-review 6-2015: PD-L1: emerging biomarker in glioblastoma? Clin. Neuropathol. 34, 313-321. doi: 10.5414/NP300922

Pukrop, T., Dehghani, F., Chuang, H.-N., Lohaus, R., Bayanga, K., Heermann, S., et al. (2010). Microglia promote colonization of brain tissue by breast cancer cells in a Wnt-dependent way. Glia 58, 1477-1489. doi: 10.1002/glia.21022

Pyonteck, S. M., Akkari, L., Schuhmacher, A. J., Bowman, R. L., Sevenich, L., Quail, D. F., et al. (2013). CSF-1R inhibition alters macrophage polarization and blocks glioma progression. Nat. Med. 19, 1264-1272. doi: 10.1038/nm.3337

Quail, D. F., Bowman, R. L., Akkari, L., Quick, M. L., Schuhmacher, A. J., Huse, J. T., et al. (2016). The tumor microenvironment underlies acquired resistance to CSF-1R inhibition in gliomas. Science 352:aad3018. doi: 10.1126/science. aad 3018

Quan, Z., Zheng, D., and Qing, H. (2017). Regulatory roles of long non-coding RNAs in the central nervous system and associated neurodegenerative diseases. Front. Cell. Neurosci. 11:175. doi: 10.3389/fncel.2017.00175

Quesenberry, P. J., Aliotta, J., Deregibus, M. C., and Camussi, G. (2015). Role of extracellular RNA-carrying vesicles in cell differentiation and reprogramming. Stem Cell Res. Ther. 6:153. doi: 10.1186/s13287-015-0150-x

Quezada, C., Peigñan, L., Segura, R., Riquelme, F., Melo, R., Rojas, Z. D., et al. (2011). Study of resistance to chemotherapy mediated by ABC transporters in biopsies of glioblastoma multiforme. Rev. Med. Chil. 139, 415-424. doi: 10.4067/S0034-98872011000400001

Qureshi, I. A., and Mehler, M. F. (2012). Emerging roles of non-coding RNAs in brain evolution, development, plasticity and disease. Nat. Rev. Neurosci. 13, 528-541. doi: 10.1038/nrn3234

Ransohoff, R. M., and El Khoury, J. (2016). Microglia in health and disease. Cold Spring Harb. Perspect. Biol. 8:a020560. doi: 10.1101/cshperspect.a02 0560

Rath, B. H., Fair, J. M., Jamal, M., Camphausen, K., and Tofilon, P. J. (2013). Astrocytes enhance the invasion potential of glioblastoma stem-like cells. PLoS One 8:e54752. doi: 10.1371/journal.pone.0054752

Rickert, U., Grampp, S., Wilms, H., Spreu, J., Knerlich-Lukoschus, F., HeldFeindt, J., et al. (2014). Glial cell line-derived neurotrophic factor family members reduce microglial activation via inhibiting p38MAPKs-mediated inflammatory responses. J. Neurodegener. Dis. 2014:369468. doi: 10.1155/2014/ 369468

Rimkus, T. K., Carpenter, R. L., Qasem, S., Chan, M., and Lo, H.-W. (2016). Targeting the sonic hedgehog signaling pathway: review of smoothened and GLI inhibitors. Cancers 8:E22. doi: 10.3390/cancers8020022

Ringertz, N. (1950). Grading of gliomas. Acta Pathol. Microbiol. Scand. 27, 51-64. doi: 10.1111/j.1699-0463.1950.tb05192.x

Rios, A., Hsu, S. H., Blanco, A., Buryanek, J., Day, A. L., McGuire, M. F., et al. (2016). Durable response of glioblastoma to adjuvant therapy consisting of temozolomide and a weekly dose of AMD3100 (plerixafor), a CXCR4 inhibitor, together with lapatinib, metformin and niacinamide. Oncoscience 3, 156-163. doi: $10.18632 /$ oncoscience. 311
Rizzi, C., Tiberi, A., Giustizieri, M., Marrone, M. C., Gobbo, F., Carucci, N. M., et al. (2018). NGF steers microglia toward a neuroprotective phenotype. Glia 66, 1395-1416. doi: 10.1002/glia.23312

Roberts, A. B., and Wakefield, L. M. (2003). The two faces of transforming growth factor in carcinogenesis. Proc. Natl. Acad. Sci. U.S.A. 100, 8621-8623. doi: $10.1073 /$ pnas. 1633291100

Rodero, M., Marie, Y., Coudert, M., Blondet, E., Mokhtari, K., Rousseau, A., et al. (2008). Polymorphism in the microglial cell-mobilizing CX3CR1 gene is associated with survival in patients with glioblastoma. J. Clin. Oncol. 26, 5957-5964. doi: 10.1200/JCO.2008.17.2833

Roesch, S., Rapp, C., Dettling, S., and Herold-Mende, C. (2018). When immune cells turn bad-tumor-associated microglia/macrophages in glioma. Int. J. Mol. Sci. 19:E436. doi: 10.3390/ijms19020436

Roessler, K., Suchanek, G., Breitschopf, H., Kitz, K., Matula, C., Lassmann, H., et al. (1995). Detection of tumor necrosis factor-alpha protein and messenger RNA in human glial brain tumors: comparison of immunohistochemistry with in situ hybridization using molecular probes. J. Neurosurg. 83, 291-297. doi: 10.3171/jns.1995.83.2.0291

Roggendorf, W., Strupp, S., and Paulus, W. (1996). Distribution and characterization of microglia/macrophages in human brain tumors. Acta Neuropathol. 92, 288-293. doi: 10.1007/s004010050520

Roos, A., Ding, Z., Loftus, J. C., and Tran, N. L. (2017). Molecular and microenvironmental determinants of glioma stem-like cell survival and invasion. Front. Oncol. 7:120. doi: 10.3389/fonc.2017.00120

Roy, L.-O., Poirier, M.-B., and Fortin, D. (2015). Transforming growth factorbeta and its implication in the malignancy of gliomas. Target. Oncol. 10, 1-14. doi: 10.1007/s11523-014-0308-y

Royet, A., Broutier, L., Coissieux, M.-M., Malleval, C., Gadot, N., Maillet, D., et al. (2017). Ephrin-B3 supports glioblastoma growth by inhibiting apoptosis induced by the dependence receptor EphA4. Oncotarget 8, 23750-23759. doi: 10.18632 /oncotarget.16077

Rycaj, K., and Tang, D. G. (2015). Cell-of-origin of cancer versus cancer stem cells: assays and interpretations. Cancer Res. 75, 4003-4011. doi: 10.1158/0008-5472. CAN-15-0798

Sadahiro, H., Kang, K.-D., Gibson, J. T., Minata, M., Yu, H., Shi, J., et al. (2018). Activation of the receptor tyrosine kinase AXL regulates the immune microenvironment in glioblastoma. Cancer Res. 78, 3002-3013. doi: 10.1158/ 0008-5472.CAN-17-2433

Sasaki, A., Yamaguchi, H., Horikoshi, Y., Tanaka, G., and Nakazato, Y. (2004). Expression of glucose transporter 5 by microglia in human gliomas. Neuropathol. Appl. Neurobiol. 30, 447-455. doi: 10.1111/j.1365-2990.2004. 00556.x

Satoh, J., Kino, Y., Asahina, N., Takitani, M., Miyoshi, J., Ishida, T., et al. (2016). TMEM119 marks a subset of microglia in the human brain. Neuropathology 36, 39-49. doi: 10.1111/neup.12235

Shi, Z., Yang, W.-M., Chen, L.-P., Yang, D.-H., Zhou, Q., Zhu, J., et al. (2012). Enhanced chemosensitization in multidrug-resistant human breast cancer cells by inhibition of IL-6 and IL-8 production. Breast Cancer Res. Treat. 135, 737-747. doi: 10.1007/s10549-012-2196-0

Sielska, M., Przanowski, P., Wylot, B., Gabrusiewicz, K., Maleszewska, M., Kijewska, M., et al. (2013). Distinct roles of CSF family cytokines in macrophage infiltration and activation in glioma progression and injury response. J. Pathol. 230, 310-321. doi: 10.1002/path.4192

Silva-García, O., Valdez-Alarcón, J. J., and Baizabal-Aguirre, V. M. (2014). The Wnt/ $\beta$-catenin signaling pathway controls the inflammatory response in infections caused by pathogenic bacteria. Mediators Inflamm. 2014:310183. doi: 10.1155/2014/310183

Solga, A. C., Pong, W. W., Kim, K.-Y., Cimino, P. J., Toonen, J. A., Walker, J., et al. (2015). RNA sequencing of tumor-associated microglia reveals Ccl5 as a stromal chemokine critical for neurofibromatosis-1 glioma growth. Neoplasia 17, 776-788. doi: 10.1016/j.neo.2015.10.002

Stupp, R., Hegi, M. E., Gilbert, M. R., and Chakravarti, A. (2007). Chemoradiotherapy in malignant glioma: standard of care and future directions. J. Clin. Oncol. 25, 4127-4136. doi: 10.1200/JCO.2007.11.8554

Stupp, R., Hegi, M. E., Mason, W. P., van den Bent, M. J., Taphoorn, M. J. B., Janzer, R. C., et al. (2009). Effects of radiotherapy with concomitant and adjuvant temozolomide versus radiotherapy alone on survival in glioblastoma in a randomised phase III study: 5-year analysis of the 
EORTC-NCIC trial. Lancet. Oncol. 10, 459-466. doi: 10.1016/S1470-2045(09) 70025-7

Suryawanshi, A., Manoharan, I., Hong, Y., Swafford, D., Majumdar, T., Taketo, M. M., et al. (2015). Canonical Wnt signaling in dendritic cells regulates Th1/Th17 responses and suppresses autoimmune neuroinflammation. J. Immunol. 194, 3295-3304. doi: 10.4049/jimmunol.1402691

Tabatabaei, P., Visse, E., Bergström, P., Brännström, T., Siesjö, P., and Bergenheim, A. T. (2017). Radiotherapy induces an immediate inflammatory reaction in malignant glioma: a clinical microdialysis study. J. Neurooncol. 131, 83-92. doi: 10.1007/s11060-016-2271-1

Tanaka, T., Oh-Hashi, K., Shitara, H., Hirata, Y., and Kiuchi, K. (2008). NFkappaB independent signaling pathway is responsible for LPS-induced GDNF gene expression in primary rat glial cultures. Neurosci. Lett. 431, 262-267. doi: 10.1016/j.neulet.2007.11.051

Tchirkov, A., Rolhion, C., Bertrand, S., Doré, J. F., Dubost, J. J., and Verrelle, P. (2001). IL-6 gene amplification and expression in human glioblastomas. Br. J. Cancer 85, 518-522. doi: 10.1054/bjoc.2001.1942

Thakkar, J. P., Dolecek, T. A., Horbinski, C., Ostrom, Q. T., Lightner, D. D., Barnholtz-Sloan, J. S., et al. (2014). Epidemiologic and molecular prognostic review of glioblastoma. Cancer Epidemiol. Biomarkers Prev. 23, 1985-1996. doi: 10.1158/1055-9965.EPI-14-0275

Tili, E., Michaille, J.-J., Wernicke, D., Alder, H., Costinean, S., Volinia, S., et al. (2011). Mutator activity induced by microRNA-155 (miR-155) links inflammation and cancer. Proc. Natl. Acad. Sci. U.S.A. 108, 4908-4913. doi: $10.1073 /$ pnas.1101795108

Tseng, D., Vasquez-Medrano, D. A., and Brown, J. M. (2011). Targeting SDF1/CXCR4 to inhibit tumour vasculature for treatment of glioblastomas. $\mathrm{Br}$. J. Cancer 104, 1805-1809. doi: 10.1038/bjc.2011.169

Turcan, S., Rohle, D., Goenka, A., Walsh, L. A., Fang, F., Yilmaz, E., et al. (2012). IDH1 mutation is sufficient to establish the glioma hypermethylator phenotype. Nature 483, 479-483. doi: 10.1038/nature10866

Turkowski, K., Brandenburg, S., Mueller, A., Kremenetskaia, I., Bungert, A. D., Blank, A., et al. (2018). VEGF as a modulator of the innate immune response in glioblastoma. Glia 66, 161-174. doi: 10.1002/glia.23234

Tzelepi, V., Karlou, M., Wen, S., Hoang, A., Logothetis, C., Troncoso, P., et al. (2011). Expression of hedgehog pathway components in prostate carcinoma microenvironment: shifting the balance towards autocrine signalling. Histopathology 58, 1037-1047. doi: 10.1111/j.1365-2559.2011.03860.x

Uhlemann, R., Gertz, K., Boehmerle, W., Schwarz, T., Nolte, C., Freyer, D., et al. (2016). Actin dynamics shape microglia effector functions. Brain Struct. Funct. 221, 2717-2734. doi: 10.1007/s00429-015-1067-y

Urbańska, K., Sokołowska, J., Szmidt, M., and Sysa, P. (2014). Glioblastoma multiforme - an overview. Contemp. Oncol. 18, 307-312. doi: 10.5114/wo.2014. 40559

Vakilian, A., Khorramdelazad, H., Heidari, P., Sheikh Rezaei, Z., and Hassanshahi, G. (2017). CCL2/CCR2 signaling pathway in glioblastoma multiforme. Neurochem. Int. 103, 1-7. doi: 10.1016/j.neuint.2016.12.013

van der Vos, K. E., Abels, E. R., Zhang, X., Lai, C., Carrizosa, E., Oakley, D., et al. (2016). Directly visualized glioblastoma-derived extracellular vesicles transfer RNA to microglia/macrophages in the brain. Neuro Oncol. 18, 58-69. doi: 10.1093/neuonc/nov244

Wallace, D. C. (2012). Mitochondria and cancer. Nat. Rev. Cancer 12, 685-698. doi: $10.1038 / \mathrm{nrc} 3365$

Wang, H., Lathia, J. D., Wu, Q., Wang, J., Li, Z., Heddleston, J. M., et al. (2009). Targeting interleukin 6 signaling suppresses glioma stem cell survival and tumor growth. Stem Cells 27, 2393-2404. doi: 10.1002/ stem. 188

Wang, Q., Hu, B., Hu, X., Kim, H., Squatrito, M., Scarpace, L., et al. (2017). Tumor evolution of glioma-intrinsic gene expression subtypes associates with immunological changes in the microenvironment. Cancer Cell 32, 42.e6-56.e6. doi: 10.1016/j.ccell.2017.06.003

Wang, S.-C., Hong, J.-H., Hsueh, C., and Chiang, C.-S. (2012). Tumor-secreted SDF-1 promotes glioma invasiveness and TAM tropism toward hypoxia in a murine astrocytoma model. Lab. Invest. 92, 151-162. doi: 10.1038/labinvest. 2011.128

Ward, P. S., Patel, J., Wise, D. R., Abdel-Wahab, O., Bennett, B. D., Coller, H. A., et al. (2010). The common feature of leukemia-associated IDH1 and IDH2 mutations is a neomorphic enzyme activity converting alpha-ketoglutarate to 2-hydroxyglutarate. Cancer Cell 17, 225-234. doi: 10.1016/j.ccr.2010. 01.020

Wesolowska, A., Kwiatkowska, A., Slomnicki, L., Dembinski, M., Master, A., Sliwa, M., et al. (2008). Microglia-derived TGF- $\beta$ as an important regulator of glioblastoma invasion - an inhibition of TGF- $\beta$-dependent effects by shRNA against human TGF- $\beta$ type II receptor. Oncogene 27, 918-930. doi: 10.1038/sj. onc. 1210683

Wick, W., Platten, M., and Weller, M. (2001). Glioma cell invasion: regulation of metalloproteinase activity by TGF-beta. J. Neurooncol. 53, 177-185. doi: 10.1023/A:1012209518843

Wirsching, H.-G., and Weller, M. (2016). The role of molecular diagnostics in the management of patients with gliomas. Curr. Treat. Options Oncol. 17:51. doi: 10.1007/s11864-016-0430-4

Xia, S., Lal, B., Tung, B., Wang, S., Goodwin, C. R., and Laterra, J. (2016). Tumor microenvironment tenascin- $\mathrm{C}$ promotes glioblastoma invasion and negatively regulates tumor proliferation. Neuro Oncol. 18, 507-517. doi: 10.1093/neuonc/ nov171

Xu, J., Zhang, X., Qian, Q., Wang, Y., Dong, H., Li, N., et al. (2018). Histamine upregulates the expression of histamine receptors and increases the neuroprotective effect of astrocytes. J. Neuroinflammation 15:41. doi: 10.1186/ s12974-018-1068-x

Xu, S., Wei, J., Wang, F., Kong, L.-Y., Ling, X.-Y., Nduom, E., et al. (2014). Effect of miR-142-3p on the M2 macrophage and therapeutic efficacy against murine glioblastoma. J. Natl. Cancer Inst. 106:dju162. doi: 10.1093/jnci/ dju 162

Xue, N., Zhou, Q., Ji, M., Jin, J., Lai, F., Chen, J., et al. (2017). Chlorogenic acid inhibits glioblastoma growth through repolarizating macrophage from M2 to M1 phenotype. Sci. Rep. 7:39011. doi: 10.1038/srep39011

Yang, J.-K., Yang, J.-P., Tong, J., Jing, S.-Y., Fan, B., Wang, F., et al. (2017). Exosomal miR-221 targets DNM3 to induce tumor progression and temozolomide resistance in glioma. J. Neurooncol. 131, 255-265. doi: 10.1007/ s11060-016-2308-5

Ye, X., Xu, S., Xin, Y., Yu, S., Ping, Y., Chen, L., et al. (2012). Tumor-associated microglia/macrophages enhance the invasion of glioma stem-like cells via TGF- $\beta 1$ signaling pathway. J. Immunol. 189, 444-453. doi: 10.4049/jimmunol. 1103248

Yeung, Y., McDonald, K., Grewal, T., and Munoz, L. (2013). Interleukins in glioblastoma pathophysiology: implications for therapy. Br. J. Pharmacol. 168, 591-606. doi: 10.1111/bph.12008

Yoshimura, T., Robinson, E. A., Tanaka, S., Appella, E., Kuratsu, J., and Leonard, E. J. (1989). Purification and amino acid analysis of two human glioma-derived monocyte chemoattractants. J. Exp. Med. 169, 1449-1459. doi: 10.1084/jem.169. 4.1449

Zhang, E., Gu, J., and Xu, H. (2018). Prospects for chimeric antigen receptormodified T cell therapy for solid tumors. Mol. Cancer 17:7. doi: 10.1186/s12943018-0759-3

Zhang, I., Alizadeh, D., Liang, J., Zhang, L., Gao, H., Song, Y., et al. (2016). Characterization of arginase expression in glioma-associated microglia and macrophages. PLoS One 11:e0165118. doi: 10.1371/journal.pone. 0165118

Zhang, J., Sarkar, S., Cua, R., Zhou, Y., Hader, W., and Yong, V. W. (2012). A dialog between glioma and microglia that promotes tumor invasiveness through the CCL2/CCR2/interleukin-6 axis. Carcinogenesis 33, 312-319. doi: $10.1093 /$ carcin/bgr289

Zhang, L., Alizadeh, D., Van Handel, M., Kortylewski, M., Yu, H., and Badie, B. (2009). Stat 3 inhibition activates tumor macrophages and abrogates glioma growth in mice. Glia 57, 1458-1467. doi: 10.1002/glia.20863

Zhang, M.-L., Zhang, X.-J., Kang, J., Zhang, H.-J., Chen, X.-L., Liu, N., et al. (2017). Matrine promotes NT3 expression in CNS cells in experimental autoimmune encephalomyelitis. Neurosci. Lett. 649, 100-106. doi: 10.1016/j.neulet.2017. 04.005

Zhang, W., Couldwell, W. T., Simard, M. F., Song, H., Lin, J. H., and Nedergaard, M. (1999). Direct gap junction communication between malignant glioma cells and astrocytes. Cancer Res. 59, 1994-2003.

Zhang, X., Rao, A., Sette, P., Deibert, C., Pomerantz, A., Kim, W. J., et al. (2016). IDH mutant gliomas escape natural killer cell immune surveillance by downregulation of NKG2D ligand expression. Neuro Oncol. 18, 1402-1412. doi: 10.1093/neuonc/now061 
Zhang, Z.-M., Yang, Z., and Zhang, Z. (2015). Distribution and characterization of tumor-associated macrophages/microglia in rat C6 glioma. Oncol. Lett. 10, 2442-2446. doi: 10.3892/ol.2015.3533

Zhao, L., Wang, Y., Xue, Y., Lv, W., Zhang, Y., and He, S. (2015). Critical roles of chemokine receptor CCR5 in regulating glioblastoma proliferation and invasion. Acta Biochim. Biophys. Sin. 47, 890-898. doi: 10.1093/abbs/ gmv095

Zhao, X., Chen, R., Liu, M., Feng, J., Chen, J., and Hu, K. (2017). Remodeling the blood-brain barrier microenvironment by natural products for brain tumor therapy. Acta Pharm. Sin. B 7, 541-553. doi: 10.1016/j.apsb.2017. 07.002

Zheng, P.-P., van der Weiden, M., van der Spek, P. J., Vincent, A. J. P. E., and Kros, J. M. (2012). Isocitrate dehydrogenase $1 \mathrm{R} 132 \mathrm{H}$ mutation in microglia/macrophages in gliomas. Cancer Biol. Ther. 13, 836-839. doi: 10.4161/cbt.20836

Zhu, W., Carney, K. E., Pigott, V. M., Falgoust, L. M., Clark, P. A., Kuo, J. S., et al. (2016). Glioma-mediated microglial activation promotes glioma proliferation and migration: roles of $\mathrm{Na}+/ \mathrm{H}+$ exchanger isoform 1. Carcinogenesis 37, 839-851. doi: 10.1093/carcin/bgw068
Zhuang, Z., Huang, J., Cepero, M. L., and Liebl, D. J. (2011). Eph signaling regulates gliotransmitter release. Commun. Integr. Biol. 4, 223-226. doi: 10.4161/cib.4.2. 14507

Zong, H., Parada, L. F., and Baker, S. J. (2015). Cell of origin for malignant gliomas and its implication in therapeutic development. Cold Spring Harb. Perspect. Biol. 7:a020610. doi: 10.1101/CSHPERSPECT.A020610

Conflict of Interest Statement: The authors declare that the research was conducted in the absence of any commercial or financial relationships that could be construed as a potential conflict of interest.

Copyright (c) 2018 Matias, Balça-Silva, da Graça, Wanjiru, Macharia, Nascimento, Roque, de Mattos Coelho-Aguiar, Pereira, Dos Santos, Pessoa, Lima, Schanaider, Ferrer, Spohr and Moura-Neto. This is an open-access article distributed under the terms of the Creative Commons Attribution License (CC BY). The use, distribution or reproduction in other forums is permitted, provided the original author(s) and the copyright owner(s) are credited and that the original publication in this journal is cited, in accordance with accepted academic practice. No use, distribution or reproduction is permitted which does not comply with these terms. 